NBER WORKING PAPER SERIES

\title{
ASYMMETRIC EFFECTS OF NON-PECUNIARY SIGNALS ON SEARCH AND PURCHASE BEHAVIOR FOR ENERGY-EFFICIENT DURABLE GOODS
}

\author{
J. Scott Holladay \\ Jacob LaRiviere \\ David M. Novgorodsky \\ Michael Price \\ Working Paper 22939 \\ http://www.nber.org/papers/w22939 \\ NATIONAL BUREAU OF ECONOMIC RESEARCH \\ 1050 Massachusetts Avenue \\ Cambridge, MA 02138 \\ December 2016
}

We thank the Baker Center at University of Tennessee and Becker Center at University of Chicago for funding support and help in executing the experiment. Wooju Lee provided excellent research assistance. We thank our private and public sector partners for their support. Ben Gilbert, Michael Greenstone, Grant Jacobsen, Steven Levitt, John List, Preston McAfee, Justin Rao, and Dmitry Taubinksy and seminar participants at the 2014 EEE NBER Summer Institute, 2014 ERE World Congress, 2014 Camp Resources, 2015 AEA meetings, 2015 Fall APPAM Conference, University of Wyoming and UC Davis all provided important feedback that greatly improved this paper. Any mistakes are ours. The views expressed herein are those of the authors and do not necessarily reflect the views of the National Bureau of Economic Research.

NBER working papers are circulated for discussion and comment purposes. They have not been peer-reviewed or been subject to the review by the NBER Board of Directors that accompanies official NBER publications.

(C 2016 by J. Scott Holladay, Jacob LaRiviere, David M. Novgorodsky, and Michael Price. All rights reserved. Short sections of text, not to exceed two paragraphs, may be quoted without explicit permission provided that full credit, including $\odot$ notice, is given to the source. 
Asymmetric Effects of Non-Pecuniary Signals on Search and Purchase Behavior for Energy-Efficient Durable Goods

J. Scott Holladay, Jacob LaRiviere, David M. Novgorodsky, and Michael Price

NBER Working Paper No. 22939

December 2016

JEL No. C93,D01,D83,Q41

\section{ABSTRACT}

We report the results of a field experiment where we exogenously vary the use of social comparisons "nudges" and subsidies for participation in an in-home energy audit program, and follow subjects through to the subsequent purchase of durable goods. We therefore can compare the causal effect of financial incentives and nudges along two margins, audits, which we liken to search, and purchase of durables. Using data on nearly 100,000 households, we document an asymmetry; nudges increase audits, but lead to lower rates of purchase. We find no evidence of a differential response for those offered a financial incentive. These differences suggest heterogeneity in the motives of the marginal consumer induced by nudges versus prices.

\author{
J. Scott Holladay \\ The University of Tennessee \\ 515 Stokely Management Center \\ Knoxville, TN 37996 \\ jhollad3@utk.edu \\ Jacob LaRiviere \\ Microsoft \\ Department of Economics \\ University of Tennessee \\ 525 Stokely Management Center \\ Knoxville, TN 37996-0550 \\ jlariv@microsoft.com
}

\author{
David M. Novgorodsky \\ University of Chicago \\ Saieh Hall for Economics \\ 1126 E. 59th St. \\ Chicago IL, 60637 \\ davidnov@uchicago.edu \\ Michael Price \\ Experimental Economics Center \\ Andrew Young School of Policy Studies \\ Georgia State University \\ P.O. Box 3992 \\ Atlanta, GA 30302-3992 \\ and NBER \\ mprice25@gsu.edu
}




\section{Introduction}

There is a growing body of literature documenting that individuals respond to social comparisons that provide informative signals about the actions or beliefs of reference groups. Specifically, such messages have been shown to influence a wide array of activities from residential electricity and water use (Allcott, 2011; Brent et al., 2015; Costa and Kahn, 2013; Ferraro and Price, 2013; Gromet et al., 2013; Ito et al., 2013; Schutlz et al., 2007) to charitable giving (Chen et al., 2010; Frey and Meier, 2004; Shang and Croson, 2009) and retirement savings (Beshears et al., 2015; Esther Duflo, 2003). To date, this literature has focused predominantly on decisions along an intensive margin (e.g., changes in electricity use, changes in water use, or average contribution levels). A less studied question is the impact of such signals on patterns of information acquisition and subsequent decisions along an extensive margin (e.g., the purchase of energy-saving technologies).

In this paper, we report the results of a natural field experiment designed to link the content of a targeted advertisement to search intensity and search to subsequent purchase decisions. Our context is participation in a utility-sponsored in-home energy audit program (IHEA) and the resulting purchase of energy-efficient durable goods. ${ }^{1}$ We compare the relative impact of pecuniary incentives, in the form of randomly-varied subsidies ${ }^{2}$, with the effects of informative nudges in the form of social comparisons that vary the unit of comparison (e.g., monthly kWh of use, monthly expenditures for energy, or $\mathrm{CO}_{2}$ emissions due to energy use) on the likelihood a household signs up for an IHEA (e.g., search for information about energy savings) and subsequently purchases a range of energy-efficient durable goods.

\footnotetext{
${ }^{1}$ We view participation in an IHEA as an act akin to costly search behavior: a household must pay a cost (in both money and time) to reduce uncertainty in the expected monetary benefit of a durable good investment. In doing so, we build upon prior work showing that many individuals systematically underestimate the relative energy intensity of many durables in the home (Attari et al., 2010) and a related body of work showing that individuals have difficulty calculating the long-run cost savings from purchasing energy efficient durable goods (Allcott and Greenstone, 2012).

${ }^{2}$ We use the terms "subsidy" and "rebate" interchangeably throughout.
} 
In the field experiment, we partnered with a utility and electricity wholesaler to send letters encouraging the household to sign-up for an in-home energy audit. Our experiment was conducted in a medium-sized metropolitan statistical area (MSA) in the southeastern United States and includes information on IHEA participation for a large control group that did not receive any letter or encouragement to schedule such. During the experiment, we mailed letters to approximately 51,000 residential consumers over five waves. All letters stated that any durable good purchases by the household that satisfied a broad range of criteria would be eligible for a rebate that provided a dollar-for-dollar subsidy on the first $\$ 1000$ spent on eligible durables (i.e., households that completed an IHEA would be eligible for a $\$ 500$ rebate on durable good purchases). ${ }^{3}$

Our experiment includes 12 different treatments arranged in a four-by-three design. Each household in the treatment group received a letter with one of four possible signals of historical electricity use and one of three possible rebate levels offered for scheduling an IHEA. The signals can broadly be delineated by: a) whether or not a household's own use was presented together with average historical use in their nine-digit zip code (No Comparison vs. Comparison), and b) the unit used to convey historical use (monthly kWHs, monthly expenditures on electricity, or $\mathrm{CO}_{2}$ emissions). ${ }^{4}$ Households receiving the No Comparison letter were provided information on their average monthly consumption in $\mathrm{kWhs}$ over the prior twelve month period. Households receiving one of the Comparison letters were provided this same information along with information on the average monthly use of counterparts in their local area. Information in the Comparison treatments was conveyed in one of three forms; (i) monthly kWhs consumed, (ii) monthly expenditures in dollars, or (iii) pounds of $\mathrm{CO}_{2}$ attributable to their monthly electricity consumption. We cross the comparison types with treatments that offer the recipient a $\$ 20$ or $\$ 50$ gift card that can be used to

\footnotetext{
${ }^{3}$ Eligible durable goods include new energy-saving windows, insulation, duct sealing, etc.

${ }^{4}$ We use nine-digit zip code averages for the local areas with 10 or more households. For smaller nine-digit zip areas we use five-digit zip averages. Throughout, wherever we refer to nine-digit zip codes, this caveat applies.
} 
offset the cost of the IHEA which was $\$ 50$ over the entirety of the study period. In this regard, our subsidy treatment introduced random variation in the price of the audit.

Our design and context allow us to overcome several challenges faced in prior work exploring the role of targeted messages (advertisements) on the economic behaviors we study. First, our design permits us to separately estimate the effect of the informational content of a message (i.e., a description of the program or information about a household's average electricity use) and the marginal effect of augmenting such messages to include a social comparison (i.e., information that compares one's own actions to the actions of like others) on search behavior. Second, we are able to place a monetary value on social comparisons by comparing the effects of these treatments to the effect of changing the price of the IHEA in our No Comparison treatment. Third, households in our subsidy treatment were required to schedule the IHEA within thirty days of receiving our letter to qualify for the gift card. By design, our program places a time limit on potential treatment effects which allows us to circumvent the challenge of open-ended search (Lewis and Rao, 2015). Finally, while the regional wholesaler schedules initial audits and provides a list of approved contractors, they do not follow up with households to encourage them to complete the recommended installations; it is the household's responsibility to qualify for the $\$ 500$ rebate. Our context is thus an ideal setting to observe the impact of our treatments on both search intensity and subsequent purchase decisions. ${ }^{5}$

We find three main results for treatment's impact on IHEA uptake. First, receiving a letter that provided information on the IHEA program and a household's average consumption, but no nudge or subsidy, had no significant impact on IHEA uptake. Second, "nudges" in the form of social comparisons are an effective strategy for promoting IHEAs. Households that receive either a kWh or expenditure comparison were more than twice as likely to schedule an IHEA than are

\footnotetext{
${ }^{5}$ In this regard, our approach differs from the IHEA program studied in Allcott and Greenstone (2015) which provides more support for households following the initial audit as a way to increase both participation in the IHEA and subsequent purchases.
} 
counterparts in the control group. Finally, consistent with the literature we find demand for IHEAs is somewhat inelastic: subsidizing audits led to statistically significant increases in IHEA rates, but even when audits were costless in monetary terms (\$50 subsidy) rates were still low. We can, though, price out a $\mathrm{kWh}$ and expenditure comparison to be $\$ 35-\$ 50$ in subsidies based upon our point estimates in terms of IHEA uptake.

With respect to durable good purchases, we find that households in the both the $\mathrm{kWh}$ and expenditure treatments were less likely to make an installation than were counterparts in the control. Importantly, these differences hold whether we examine installations conditioned on completing an IHEA or examine the unconditional effect of treatment on the purchase decision. Conversely, purchase rates for households in our subsidy treatments are statistically indistinguishable from those observed amongst the control group. Taken jointly, these differences suggest heterogeneity in the motives of the marginal consumer that is induced to take the audit across treatments. We find evidence that nudges were less effective at inducing installations than subsidies but more effective at leading to additional audits.

The findings highlight that what motivates the marginal auditor (e.g., search behavior) versus the marginal durable goods installer (e.g., purchase behavior) can vary as a function of pecuniary and non-pecuniary signals. For example, in our experiment a $\$ 50$ subsidy and $\mathrm{kWh}$ comparison had similar impacts on IHEAs but different impacts on durable good purchase. Our finding is consistent with there not being a one-to-one mapping between social comparisons and price signals across all microeconomic behavior. We don't view this finding as particularly surprising however as the literature remains unsettled as to all the precise mechanisms through which social comparisons operate despite recent advances (Allcott and Kessler, 2015).

The next section motivates IHEAs as a form of search and describes the field experiment. Section 3 presents data. Section 4 presents results and offers discussion. Section 5 briefly concludes. 


\section{Audits as Search}

We follow Gilbert et al. (2015) and argue that IHEAs are a form of search. The canonical search literature motivates search in the context of a consumer acquiring product information via brick and mortar shopping before making a purchase (Rothschild, 1974). However, brick and mortar shopping is not the only way an individual can engage in search. Seeking expert advice can also be modeled as a form of search (e.g., Pitchik and Schotter (1987) and Edo and Szentes (2007)). In such models, the agent seeking advice is uncertain about the state of the world but can learn about it by paying for an informative signal from an expert. As a result, the agent undertakes a costly action - paying an expert - as a way to acquire information before making a purchase decision.

When a consumer signs up for an IHEA, they are seeking expert advice about the benefits of making an investment in an energy-efficient durable good. During an IHEA, a paid professional enters a home and uses specialized equipment to identify a range of durable good investments that, if made, would allow the household to save electricity and get the greatest possible return on their investment. ${ }^{6}$ However, many individuals may incorrectly perceive the relative energy intensity of many actions within the home (Attari et al., 2010) or have difficulty calculating the long-run cost savings from purchasing energy efficient durables (Allcott and Greenstone, 2012; Palmer and Walls, 2015). An important function of an IHEA is that the auditor helps resolve such uncertainty and, in doing so, better anchors a household's expectations about the net present value (NPV) of investments in various durable goods. ${ }^{7}$

Our experimental treatments are designed to introduce variation in the expected net benefits of scheduling an audit and/or introduce new motives for search (social norms). In the Appendix, we

\footnotetext{
${ }^{6}$ Auditors may also provide advice on ways to reduce electricity consumption without changing the stock of durable goods in the home - e.g., by setting thermostats at a higher temperature during summer months.

${ }^{7}$ While McKinsey (2009) documents large variability in the implied rate of return across the spectrum of durable good investments that may be suggested to a household during an IHEA, auditors in our study area limit suggested installs and recommend 3 to 5 items that are ordered based on the implicit rate of return.
} 
walk through a simple theoretical model of audits as a form of search in line with Gilbert et al. (2015). We also discuss our ability to parse between the various channels through which our treatments shift expected audit benefits in greater detail below. For example, variation in the framing of the social comparison allow us to measure whether households weigh information differently when it highlights expected private benefits (expenditures) as opposed to public benefits (carbon emissions) on search and associated changes in consumption.

There are direct links between our study and measuring the returns from advertising. In general, there are two key challenges to measuring returns to advertising. The first is the data challenge of linking exogenous variation in advertising to revealed preference data on search and subsequently revealed preference sales data. The second is the nature of search and purchase: especially for high cost items like durable goods there is a significant amount of search so that even after an advertising campaign, a household may delay their purchase of a good while gathering information. Our field experiment, described in the next section, allows us to overcome both of these problems for three reasons. First, we randomly vary both the price of search and non-price signals (e.g., nudges) and are able to use administrative records to link treatment to a particular customer. This allows us to identify and directly compare the effect of the various messages on search intensity and subsequent purchase decisions. Second, we exploit a key feature of the IHEA program to track both search (e.g., audit uptake) and purchase (e.g., home durable good upgrades) for the same user over time. In our study region, households were required to have a third party auditor verify installations if they wished to claim the available rebates on purchase. We are thus able to identify treatment's impact on search and purchase behavior using administrative records. Third, our pecuniary treatment, audit cost subsidies, sets a bound on the maximum length of time available to subjects to redeem the subsidy. From a design perspective, then, we are well-suited to address time lag challenges noted in the literature and identify the effects of our treatments on both search intensity and the 
resulting purchase decisions (Lewis and Rao, 2015).

It is also important to place our paper in the context of the larger literature on nudges and economic behavior. There is a growing body of literature showing that social norms and specifically "nudges" in the form of social comparisons can be used to change patterns of electricity and water consumption (Allcott, 2011; Costa and Kahn, 2013; Brent et al., 2015; Ferraro and Price, 2013; Ito et al., 2013; Wichman et al., 2016). Moreover, given results from Ferraro et al. (2011), Bernedo et al. (2014), Allcott and Rodgers (2014) and Dolan and Metcalfe (2015) showing that social comparisons can have persistent effects on patterns of electricity and water use, it is reasonable to posit that such signals may influence patterns of search and subsequent purchase of more efficient durable goods rather than exclusively working through long-run changes in behavior. We investigate this directly in our paper by focusing on energy-efficient durable good upgrades.

We investigate nudges' ability to cause households to invest in the energy efficiency of their home, and in doing so add to the nudge and social norm literature in several novel ways. First, we investigate IHEAs and durable good investment decisions available to all households- not just low income households as in Fowlie et al. (2015). Second, our treatments exogenously vary the use of nudges, the form of nudges (private versus social frames) and the price of IHEAs providing an apples-to-apples comparison of nudges in terms of dollars. Third, because we follow subjects through the audit process to purchase, we can determine if subjects "nudged" into audits behave similarly in purchase space as subjects "priced" in through subsidies. Fourth, because we use comparisons highlighting both private aspects $(\$$ and $\mathrm{kWh})$ and public aspects $\left(\mathrm{CO}_{2}\right)$ of electricity consumption we are able to identify how framing of nudges impacts their effectiveness in the context of IHEAs. 


\section{The IHEA Program and Experimental Design}

IHEAs are widely-available programs in which a trained expert with specialized equipment examines a home and recommends the most cost-effective investments a household could make to save money on electricity bills. Local utilities and policymakers across the U.S. have implemented a range of programs designed to increase the rate of IHEAs as a means to stimulate the purchase of energyefficient durables (e.g., NYSERDA, TVA Energy Right, New Jersey Clean Energy Program, and Mass Save, among others) to reduce demand for electricity and mitigate externalities associated with its consumption. Our study area is reflective of this national trend. Like other areas, our area exhibits annual rates of IHEAs that are low (less than 1 percent), which has prompted the regional wholesaler to pursue a variety of ways to increase participation including the ideas tested in our experiment (Palmer and Walls, 2015).

Our field experiment was conducted with the support of an electric utility and their primary wholesaler which funds and administers the IHEA program. The program is branded and passively advertised on the utility's website. ${ }^{8}$ At the time of our experiment, the only way to schedule an audit was for a customer to call a hotline managed by the regional wholesaler and arrange for an auditor to come to their home at a predetermined time. At the end of the experiment, we were provided the universe of call logs for our sample area. This allows us to observe and record all audits scheduled in our sample area during the course of our experiment.

During an audit, a professionally trained auditor comes to the customer's home and performs a visual inspection. ${ }^{9}$ The auditor typically inspects the home's attic, basement and HVAC system. At the time of our experiment, the audit took approximately half an hour to complete and the

\footnotetext{
${ }^{8}$ Over the course of our experiment, there was no change in the marketing of the program by either our partner utility or the wholesaler.

${ }^{9}$ Some IHEA programs use trained engineers and infrared cameras or blower door tests to find sources of energy leakage. The program we investigate is intended to be a low cost, less time-intensive audit and provides more general information.
} 
homeowner was required to be present during this time. The audit cost $\$ 50$ but the amount was refunded if the customer made a recommended investment.

At the end of the audit, the auditor presented the customer with a list of suggested investments that could include improved insulation in the attic, replacing windows or sealing HVAC system ducts. Each customer was presented with the same list of potential investments and provided informal suggestions about which investments were likely to provide the greatest return for them specifically. In addition, customers were provided a list of approved contractors who could perform the work and informed that they would receive a dollar-for-dollar subsidy of up to $\$ 500$ for any investment on the list.

To receive the durable good subsidy, households were required to schedule a follow-up audit and provide confirmation from the auditor that the installation was done properly. The follow-up audits were scheduled by phone and noted in the log book as a verification appointment. As a result, we have administrative records on both audits and subsequent purchases in the audit program.

\subsection{Experimental Design}

As noted above, our field experiment was conducted with the support of an electric utility and their primary wholesaler. Our sample area was a medium-sized MSA in the U.S. served almost entirely by the same utility. ${ }^{10}$ The goal of the field experiment is to identify how subsidies and different forms of comparative information affect the 1) probability of signing up for an IHEA and 2) the probability of subsequently making an installation. Importantly, we worked with the utility and the wholesaler in designing the experiment so as to maintain consistency with their project goals.

Figure 1 provides a graphical depiction of the timing of subjects' decisions in our field experiment.

\footnotetext{
${ }^{10}$ In this area, the utility provides electricity to all residential customers via average cost pricing; there is no block structure for residential consumers. During the study period, the retail price of electricity for households was constant.
} 
As noted in the figure, households were first randomized into either a control group or one of twelve treatment groups that received a letter inviting them to sign up for an in-home audit. Households then determined whether or not they wished to sign up for the IHEA and call the auditing agency to schedule the audit. ${ }^{11}$ Conditional on completing an audit, households had the opportunity to purchase and install a range of energy-efficient technologies that were eligible for a rebate from the auditing agency. To receive the rebate, the household had to schedule a follow-up audit to verify the installation.

Our research design compares the relative impact of pecuniary incentives (subsidies that lower the cost of the IHEA) with the effects of social comparisons that convey relative consumption from three different frames; (i) average monthly $\mathrm{kWh}$, (ii) average monthly expenditures, and (iii) $\mathrm{CO}_{2}$ emissions related to average monthly use. The various treatment letters were designed in collaboration with the regional wholesaler. Because we cannot observe whether letters are opened or not we estimate intent-to-treat effects (ITTs) in all but one case (probability of installation conditional on audit).

Table 1 depicts the four-by-three treatment design utilized in our natural field experiment. Cell entries reflect a unique treatment letter (described below) and the corresponding number of households that received the given letter type. For example, the upper left corner of the table corresponds to our baseline - "No Comparison, No Subsidy" - treatment letter which was mailed to 3,923 distinct households. This treatment compared to the large control group allows us to estimate the informative effects of the letter on audits and installs. In total, we sent out over 50,000 letters and observe decisions for a large control group who did not receive a letter during the course of the experiment. Table 1 also shows statistically insignificant differences in average pre-treatment

\footnotetext{
${ }^{11}$ Households in the control group did not receive a letter encouraging them to sign up for an IHEA but had the same opportunity to participate in the program. Moreover, the procedure for scheduling an audit and the nature of the audits themselves were identical for households in the treatment and control groups.
} 
electricity usage by subject.

Treatment letters were printed on the electricity wholesaler's official letterhead (e.g., the entity overseeing IHEAs in the area) and sent via first-class mail in envelopes from the wholesaler to maximize the likelihood that they would be opened by the household and associated with the IHEA program. Letters were mailed across five waves starting in December 2012 through August 2013. Our utility partners required the waves to be spread over time to avoid exceeding the capacity of the existing staff of auditors. Figure 2 shows the wave-by-wave timing in a Gantt chart. While the figure describes the period of study for subjects getting audits attributable to treatment, for experimental design reasons discussed below, we observe all installations through mid-December 2013. We provide evidence below that this is sufficient coverage for our experiment.

Table 2 describes the samples sizes and date of mailing for each treatment wave. It also reports the number of households in each treatment type in each wave. Each pilot wave has around four thousand households and the three main waves varied between fifteen and twenty thousand treated households. In all, approximately 51,000 households are in one of twelve treatment groups in addition to a large control group of roughly 50,000 households (roughly 10,000 of which are held as explicitly within-wave control units).

The sample sizes are nonlinear across subsidy levels to improve power to detect nonlinear response to subsidy levels; in particular, we employed a weighted design over the various subsidy levels (25\%-50\%-25\%) which allows us to identify non-linear effects of price on likelihood of signing up for an IHEA and is the optimal sample arrangement if we believe that the underlying demand function is quadratic. Waves 1 and 2 did not include $\mathrm{CO}_{2}$ treatment types of any subsidy amount because of low uptake during the pilots. 


\subsubsection{No Comparison Letter}

Our baseline letter provided households an "information-only" message designed to encourage the recipient to sign-up for an IHEA (see Appendix). The letter included a brief description of the IHEA program along with a phone number and web address that the household could use to get more information about the program. Specifically, the letter describes the IHEA program as follows:

There's no place like home, and there's no time like now to make your home more energy efficient. You can conserve energy, save on utility bills, and get cash rebates by participating in....

If you sign up for an IHEA, a ... Certified Energy Advisor will visit your home at a time convenient for you. The advisor will recommend cost-effective ways to increase your home's energy efficiency and will install free CFLs and low-flow water saving measures if you choose.

...evaluation fee is $\$ 150$ (currently with an instant rebate of $\$ 100$ ). And you will receive the remaining $\$ 50$ fee back if you spend $\$ 150$ or more on qualifying improvements. You will also receive matching rebates of up to $\$ 500$ for installing eligible improvements....

In addition to information on the IHEA program, our baseline letter included information on the household's average monthly consumption during the preceding year. Such information was conveyed using a bar chart ${ }^{12}$ which was a statement reading “...Your average energy consumption over the past year: XXX kWh..." We calculated average monthly consumption using billing records shared with us by our partner utility. Specifically, we used monthly billing data for the period July

\footnotetext{
${ }^{12}$ This bar chart and those corresponding to our three other content-related treatments are depicted in Figure 3 side-by-side.
} 
2011 through July 2012 to calculate a household-specific measure of average monthly consumption. ${ }^{13}$

\title{
3.1.2 The Social Comparison Letters
}

We build upon the social comparison and "nudge" literature by augmenting our baseline letter to include a comparison of the household's average electricity use to the average use of other households in their nine-digit zip code. ${ }^{14}$

Information in the social comparison treatments were conveyed in one of three forms; (i) monthly kWhs consumed, (ii) monthly expenditures in dollars, or (iii) pounds of $\mathrm{CO}_{2}$ attributable to their monthly electricity consumption. ${ }^{15}$ We chose these three frames to identify if households respond to nudges which make different aspects of electrity consumption more or less salient: use $(\mathrm{kWh})$, expenditures $(\$)$ or a public bad associated with electricity consumption $\left(\mathrm{CO}_{2}\right.$ emissions $)$. Differential responses for search and purchase due to different frames would provide information about what aspects of a nudge induce subjects into changing their behavior. We included a bar chart to illustrate the comparison graphically. Below the bar chart, we included a statement reading:

\author{
Your Average Energy Consumption $\quad$ XXXkWh \\ Local Area Homes' Average Energy Consumption $\quad$ XXXkWh
}

\section{You used XX percent more (less) energy than other area homes}

Our choice of nine-digit zip rather than a higher level of aggregation as the comparison group was informed by a large body of work in social psychology showing that comparative signals are

\footnotetext{
${ }^{13}$ Households in our sample area receive bills from our partner utility on a monthly basis. While monthly bills display consumption for each of the previous 12 months, they do not provide information on average consumption over the period.

${ }^{14}$ Recall that for subjects with fewer than 10 households in a nine-digit zip, we used five-digit zip code averages.

${ }^{15}$ To our knowledge, ours is the first paper to explore how varying the way in which comparative information is framed impacts subsequent behavior. While Allcott and Greenstone (2015) present results from a field experiment that uses a variety of "nudges" to induce participation in an IHEA program, the aim of their paper is to quantify the welfare implications of such programs rather than explore whether and how such strategies influence patterns of search and subsequent purchase decisions.
} 
most effective when the reference group is more proximate to the individual receiving the signal (e.g., Trope and Liberman (2010).) We framed the percentile text depending on whether a household used more or less electricity than their local area. We interpret such framing as a way to emphasize how many people do or do not engage in the targeted behavior (e.g., Cialdini et al. (2006) and Schultz et al. (2007))

\subsubsection{The Subsidy Letters}

Our final treatment dimension is designed to introduce experimental variation in the expected net benefit of an in-home audit. To do so, we augment the baseline and social comparison letters to include a rebate for households that sign-up for an IHEA. Specifically, our subsidy treatments offered the recipient a $\$ 20$ or $\$ 50$ gift card that could be used to offset the cost of the IHEA. Information about the subsidy was included in the final sentence of the third paragraph which in part reads:

As an additional thank you for participating, if you have an In-Home Energy

Evaluation within 30 days from the date of this letter you will receive a $\$ \mathrm{XX}$ gift card.

Before proceeding to the results section, a few key features of our experimental design should be highlighted. First, within each wave of the experiment, treatment letters were mailed on the same day. ${ }^{16}$ Second, there were around 3,000 letters that were returned to sender and thus not delivered. We dropped these households from our empirical analysis. Third, households that moved or had their electricity service cut off due to delinquent bills during the course of our experiment were dropped from the analysis. Finally, all treatment letters included a unique code located at the bottom left corner. The call center recorded this code when scheduling an IHEA which allowed us

\footnotetext{
${ }^{16}$ One minor exeption occurred during the first pilot during which letters were sent across two days - December 18,2012 and December 21, 2012.
} 
to match households that scheduled an IHEA to their respective treatment group.

\section{$4 \quad$ Data and Experimental Results}

Each treatment letter had a unique identifier that matched the specific letter (and therefore treatment group) to an address. We entered into a data sharing agreement with the auditing agency and wholesaler in order to measure how treatment affected audits and installations. To do so, we first matched the universe of scheduled IHEAs to the randomized treatment and control assignments based on the address of the household. ${ }^{17}$ We next linked audit scheduling with subsequent purchase decisions, using data from the follow-up audits and the installations verified during this audit.

Letters in the subsidy treatment contained a clause noting that to guarantee the subsidy the household had to call and schedule an IHEA within 30 days of receiving the letter. ${ }^{18}$ Due to a small number of scheduling conflicts and at the suggestion of the auditor, we honored the subsidies for up to sixty days of sending the letter. For each household, we thus limit the post-intervention period to a fixed period of sixty days following the mailing of any treatment letter to estimate upper bounds for audit uptake treatment effects. All households in the area to whom this utility provides electricity (approximately 100,000 total) were subject to randomized treatment assignment.

There are two sets of results from the IHEA field experiment. The first identifies the effect of treatment on IHEA participation. The second set of results identifies the effect of treatment on installations. There are two parts to the installation results: how treatment impacts the likelihood of a purchase and how treatment impacts the timing of installs relative to control households.

\footnotetext{
${ }^{17}$ Our randomization was a block randomization on a household's mean electricity use in the preceding year with approximate blocking on which decile a household's mean use in the preceding year falls into among households in its local area. We summarize the results of this block randomization with the mean pre-treatment use in Table 1 as well as the distribution of treatment assignment in Figure A5 in the Appendix.

${ }^{18}$ Importantly, this allows us to verify the effect of advertisements (treatment) on search. Other studies note that not being able to place time limits on search complicates the problem of estimating the effects of advertisements on purchase (Lewis and Rao, 2015).
} 
We performed power tests before implementing our experiment to gauge the likelihood of finding significant results. The results of those power tests are presented in the Appendix. Due to the stated experience of the audit providers with advertising campaigns, we designed the experiment to detect treatment effects which double baseline audit and installation rates. Those results suggest that our sample size is sufficient to detect effects of treatment when all treatment groups are aggregated into one group (least granular), as well as when social comparison treatment effects are additively separable in price treatment effects and vice versa (more granular). We therefore use an empirical specification which allows a unique estimate for each comparison treatment and each subsidy level by using indicators for each type of comparison and each level of subsidy (but not the interaction). ${ }^{19}$

\subsection{Search: Treatment on IHEA Uptake}

The primary goal of the field experiment is to provide an apples-to-apples comparison of pecuniary incentives and informative "nudges" on search (e.g., IHEA uptake) and purchase behavior (e.g., durable good installation). Given the explicit time limitation built into our pecuniary treatments, we focus on IHEA uptake rates in the two months following treatment. ${ }^{20}$ As a result the two month audit uptake rate is the primary statistic of interest. As a benchmark, the two month audit uptake rate for households in the meta-control group, the right counterfactual for our analysis, is .0011.

In Table 3 we report raw 60 day IHEA uptake rates across treatments over the experimental window. ${ }^{21}$ Columns show different subsidy treatments and rows show different comparison treatments. There are several important points regarding Table 3. First, overall effects across all treatments were

\footnotetext{
${ }^{19}$ We lack power to estimate 12 unique comparison-subsidy treatment effects to gauge the impacts of the interaction of comparison and price effects but report those results in the Appendix for completeness; they are consistent with the main results presented here and statistically significant in several cases.

${ }^{20}$ Recall that, by design, households in our subsidy treatments had to schedule an IHEA within 30 days of receiving the letter to be eligible for the gift card.

${ }^{21}$ Note that Table 3 (as well as 4) drops eight IHEAs unmatched because they either occurred during a break in the billing time series or occurred precisely on the last day of a household's final bill in the time series.
} 
modest, not quite doubling two month uptake rates (.0019 relative to .0011). This is consistent with the larger literature on audit uptake which finds inducing additional audits is challenging (Fowlie et al., 2015; Palmer and Walls, 2015). Second, the "No Comparison-No Subsidy" treatment, which only included information on the audit itself, did nothing to increase uptake and potentially even decreased audit uptake (.0008 versus .0011). We don't view this as strong evidence on a significant decrease, though, given the relatively small size of the "No Comparison-No Subsidy" treatment cell. Third, expenditure and $\mathrm{kWh}$ comparisons both have a positive impact on IHEA uptake and those impacts are identical. $\mathrm{CO}_{2}$ comparisons look to have a no impact on IHEA uptake. This is consistent with findings from the larger literature that social comparisons can induce economic action (Allcott, 2011; Ferraro and Price, 2013) but that different frames can asymmetrically impact behavior (Chen and Li, 2009; Chen et al., 2010). Fourth, subsidies increased IHEA uptake but not by as much as comparisons, and there is no consistent evidence for an impact of moving from the $\$ 20$ to $\$ 50$ subsidy. This third and fourth point taken together imply that some social norms can be more valuable than either a $\$ 20$ or $\$ 50$ subsidy.

To examine the statistical significance of these findings and control for seasonality/differences in IHEA participation across waves of the experiment, we proceed from the suggestive results in Table 3 to regression-adjusted results. In such models, we separately estimate the average ITT effect of receiving any letter (which we typically associate with a variable called Any Letter) and the marginal ITT effect of different content framings (which we typically associate with a set of variables called $\mathrm{kWh}$ Comparison, $\$$ Comparison, and $\mathrm{CO}_{2}$ Comparison). ${ }^{22}$

In the estimation we collapse the panel data series to a cross sectional data series with wave-level

\footnotetext{
${ }^{22}$ While our interest is in analyzing search, we are evaluating a relevant policy instrument at the same time. In this vein, note that with any mailing, no amount of targeting on the part of policymaker solves the unobservable opening of mail, so the ITT effect is also a policy relevant treatment effect. Nonetheless, our coefficients inevitably underestimate the average treatment effect on the treated.
} 
treatment and control audit uptake indicators defined to give an apples-to-apples comparison between treatment and control groups given both multiple treatment waves and limited treatment windows to schedule an audit (e.g., 60 days). We've estimated the same specification at the month level and all results are similar but we view this as conceptually easier to interpret. We also use the entire set of super-control households randomly assigned to different waves. This gives roughly 99,000 subject households in the full estimating sample. In sum, we perform our main estimating specification via a cross-sectional OLS regression:

$$
\begin{aligned}
1\left\{\text { IHE }_{i}\right\} & =\alpha+\omega_{w}+\nu_{t z}+1\left\{\text { Any Letter }_{i}\right\} \gamma+\sum_{f \in\left\{\mathrm{kWh}, \$, \mathrm{CO}_{2}\right\}} 1\left\{f \text { Comparison }_{i}\right\} \beta_{f} \\
& +1\left\{\$ 20 \text { subsidy }_{i}\right\} \delta_{1}+1\left\{\$ 50 \text { subsidy }_{i}\right\} \delta_{2}+\epsilon_{i} .
\end{aligned}
$$

$1\left\{I H E A_{i}\right\}$ is an indicator which denotes whether household $i$ conducted an IHEA with two months of being treated. $1\left\{\right.$ Any Letter $\left._{i}\right\}$ is an indicator variable that takes the value of one if a household was randomized to receive any letter. A similar definition applies for each framing $f$ in $1\left\{f\right.$ Comparison $\left._{i}\right\}$ which allows for estimation of the marginal effect of each comparison on IHEA uptake. To explain wave-specific variation in IHEA rates, we include wave fixed effects $\omega_{w}$. To explain some time-series and spatial variation in IHEA rates and improve the precision of the estimated treatment effects, we also include fixed effects $\nu_{t z}$ capturing features of the particular month in which the audit occurred $(t)$ and the particular five-digit zip code $(z)$ where the household is located. This technique assures proper weighting of control households and that treated households are never grouped as control households (e.g., in the 61st day after a letter).

Given our baseline specification, the coefficient $\gamma$ is the "pure information" effect of receiving any letter (e.g., without a social comparison) on bi-monthly IHEA rate. $\beta_{f}$ describes the marginal effect 
for each framing $f \in\left\{\mathrm{kWh}, \$, \mathrm{CO}_{2}\right\}$ - i.e., it captures the effect of the given framing in addition to the pure information effect associated with receipt of a letter. Looking beyond non-pecuniary effects, our baseline specification also allows us to estimate the causal effect of subsidies on IHEA uptake by an indicator variable for each subsidy level (e.g., $1\left\{\$ 20\right.$ subsidy $\left._{i}\right\}$ ). Importantly, this specification will allow us to identify the dollar-equivalent of a comparison (i.e., a "nudge") by comparing the marginal effect of a subsidy to each $\beta_{f}$.

Table 4 shows the coefficient estimates from estimating equation (1). We estimate the ITT effect for the full sample in columns 1 and 2. Column 1 does not include controls for waves $\left(\omega_{w}\right)$ or for audit month-of-year by 5 -digit-zip $\left(\nu_{t z}\right)$ fixed effects whereas column 2 does. Differences in sample sizes are driven by singleton households within the fixed effects. We report results for specifications that parse the sample above and below median electricity use within a local area (columns 3 and 4 ) and above and below median electricity use for the sample area as a whole (columns 5 and 6 ). Such specifications allow us to explore whether the effects of our treatments differ across high and low user groups. We note, though, that parsing the sample in this way greatly reduces statistical power so we consider those results to be suggestive only. In each specification we use heteroskedasticity robust standard errors.

For the full sample without controls (column 1) and with controls (column 2) we find that the pure information treatment effect $\gamma$ is an imprecisely estimated zero. Moving to marginal effects, we find positive and significant effects of both the $\mathrm{kWh}$ and expenditure comparisons. The point estimate of both $\mathrm{kWh}$ or expenditure comparisons are more than double that of the control group in Column 1. Moreover, as in the raw data, we find no effect of a $\mathrm{CO}_{2}$ comparison on uptake. We emphasize that these impacts are the marginal impact of a comparison relative to the exact same information, including a subject's own average energy usage, in the treatment letter. Parsing the sample by above and below local (nine-digit zip) and MSA medians the effect of dollar comparisons 
remains significant but only for energy users below the median. Subsidies had an impact for above MSA-median households, though. While suggestive, due to lack of statistical power we don't claim strong inference from this result.

The impact of subsidies is positive but somewhat less consistent than the impact of social comparisons. A $\$ 20$ subsidy has a positive and statistically significant impact on IHEA uptake in the regression without controls but becomes insignificant in the specification with controls. The opposite is true for the $\$ 50$ subsidy: it has an insignificant impact on IHEAs without controls and significant with controls. We favor the regression with controls (column 2) since fixed effects increase the signal to noise ratio in treatment.

The subsidy results in column 2 are consistent with economic intuition on subsidies and the effectiveness of nudges. First, the point estimate for a $\$ 20$ subsidy is less than a $\$ 50$ subsidy. However the two coefficients are not statistically different from each other. Second, we find that point estimates for the statistically significant results in columns 1 and 2 put to dollar value of either a $\mathrm{kWh}$ or expenditure $(\$)$ comparison at between $\$ 35$ (column 1) and $\$ 50$ (column 2). This dollar value of a nudge is consistent with what we observe when we estimate this regression as a panel (results available upon request and presented in earlier versions of this paper).

In sum, we find that non-pecuniary signals (expenditure and use comparisons) significantly increase search intensity (audit uptake) in our experiment. Further, our results suggest that the framing of the non-pecuniary signals mattered; only privately framed comparisons increased audit uptake. $\mathrm{CO}_{2}$ comparisons have no statistically significant impact on IHEA uptake. We note that we are somewhat less confident in this $\mathrm{CO}_{2}$ comparison result given there were only half as many households in the $\mathrm{CO}_{2}$ treatment. We view this as important, though, because there is evidence that the type of framing matters and our result is consistent with that (Chen and Li, 2009; Chen et al., 2010; Costa and Kahn, 2013). 
We acknowledge that monthly IHEA uptake is small in both our study area and the nation (Palmer and Walls, 2015). Hence, even though our field experiment increased IHEA rates by over $100 \%$, we still have few households conducting IHEAs. To place these effect sizes in context, our IHEA uptake rates are actually similar to click-through rates for online banner advertisements (Lewis and Rao, 2015). Even with over 50,000 households in the treatment, treatment induced 80 additional IHEAs. This is no surprise: even when fully subsidized, IHEAs impose a time cost on households. For example, DellaVigna et al. (2016) find that households' time costs to be surveyed in their homes are on the order of $\$ 35 /$ hour. IHEAs must be scheduled in advance and, as mentioned earlier, take roughly half an hour to complete. Thus, even when there is no expenditure for an IHEA, there is still a non-trivial price for this kind of search. Taken at face value, our estimates suggest that subsidies would need to be on the order of $\$ 67.50$ in the location of our field experiment in order to make IHEAs "free" for households (e.g., $\$ 67.50=\$ 50$ IHEA price $+\$ 17.50$ time cost).

These results allow us to perform a back-of-the-envelope calculation (assuming out point estimates are externally valid) to determine the implied cost of this policy if it were widely implemented. ${ }^{23}$ We sent out out roughly 50,000 letters at 45 cents per letter (in 2012) for a total cost of $\$ 22,500$. Each audit therefore had an implicit cost of roughly $\$ 281$. There are two ways to reduce this cost. First, sending the letters by bulk would halve costs. Assuming bulk mail is opened at the same rate and by the same types of households as first class mail, the costs drop to roughly $\$ 140 /$ audit. Now assume that instead of sending each treatment, only the most effective treatments were sent: either kWh or expenditure comparisons and a $\$ 50$ subsidy. Recalling that roughly $60 \%$ of households got either a $\mathrm{kWh}$ or expenditure comparison, and only a small fraction both the $\$ 50$ subsidy and a $\mathrm{kWh}$ or expenditure comparison (e.g., .60*.25 $=.15$ ), the implied cost of using an optimized version of

\footnotetext{
${ }^{23}$ Note that this back-of-the-envelope is not necessarily of scientific interest given that we care about installations and not audits per se.
} 
this policy is roughly $\$ 85$ per audit. Paying the $\$ 50$ subsidy increases the price of an audit using this policy back to $\$ 135$ per audit.

\subsection{Purchase: Treatment on Installs}

Next we test for treatment's impact on installing a new durable good. Juxtaposing treatment's effect on durable good purchases with treatment's effect on search in a unified field experiment is the main contribution of the paper. Our context is also important for policy - if households in the treatment group are more likely to sign up for an IHEA but less unlikely to actually make an installation, it would suggest that both non-pecuniary signals ("nudges" in our case) and pecuniary incentives for IHEA participation are cost-ineffective ways to induce households to make large energy-efficient durable good upgrades. As a result, we focus on the behavior of "nudged in" subjects versus "priced in" subjects versus control subjects in terms of installation behavior.

As a first step we investigate the timing decision of treated versus control households who make installations relative to when they schedule an audit. This provides a view of not just total effects on installations but also to possible differences in those mechanisms. This is also important to verify the internal validity of the experiment: our installation data are through Dec 15, 2013 and the final wave of letters was sent on August 12, 2013. If there is a significant time gap between audits and installations we may not have complete coverage and thus underestimate the likelihood of installations. We investigate the impact of treatment on installations in great detail below, but note that the likelihood of an installation conditional on an audit in control households is roughly $66 \%$.

Figure 4 is a histogram illustrating the number of days between an initial IHEA and an installation for all households in the experimental sample making an installation. The figure shows two important characteristics of installation behavior: first, almost $50 \%$ of installations occur on 
the same day as the audit. Second, almost all installations occur within three months of the initial audit. This is reassuring given our data only runs for 120 days after the final wave of letters was sent and the letters stated audits must be scheduled within 30 days of treatment.

Table 5 parses average installation timing by treatment and control group. Control households have an average delay between initial audit and install of 41.5 days and treated households 27.6 days. This difference is preserved when only including the pilots and waves one and two. This shows weak evidence that treatment decreases time to make an install. We exclude regression results but note similar findings with statistically significant negative differences at the $10 \%$ level for $\mathrm{kWh}$ comparisons only. This is consistent with the idea that treated households view the audit and installation procedure as more salient: treated households act more quickly than untreated. While we acknowledge truncation of the data in December 2013 would lead to downward bias in the likelihood of installations conditional on an audit, we view these results as strong evidence we have very good coverage of treated installations.

Turning to treated households' propensity to make durable good purchases, we estimate treatment's effect on durable good purchases in two ways. First, we estimate the unconditional effect of treatment on making an installation for all households in the sample. Second, we estimate the effect of treatment on installations conditional on households who scheduled audits. While the first specification captures the policy relevant effects, we believe that the second is more interesting from an economic perspective. Specifically, the second specification allows us to derive an apples to apples comparison of the likelihood of making a durable good purchase for control subjects who self-select into an IHEA and subjects who are "nudged" or "priced" into an IHEA by treatment.

To identify the unconditional effect of treatment on installations, we estimate the following 
model:

$$
\begin{aligned}
1\left\{\text { Any Install }_{i}\right\} & =\alpha+\omega_{w}+\pi_{m}+\eta_{t z}+1\left\{\text { Any Letter }_{i}\right\} \gamma+\sum_{f \in\left\{\mathrm{kWh}, \$, \mathrm{CO}_{2}\right\}} 1\left\{f \text { Comparison }_{i}\right\} \beta_{f} \\
& +1\left\{\$ 20 \text { subsidy }_{i}\right\} \delta_{1}+1\left\{\$ 50 \text { subsidy }_{i}\right\} \delta_{2}+\epsilon_{i}
\end{aligned}
$$

As before, we study the cross section of roughly 99,000 households who we identified as non-movers. Collapsing to a cross section handles heterogeneity in the time lag between when a household schedules their initial IHEA and the final inspection IHEA to verify a installation occurred. ${ }^{24}$

The left-hand side variable in equation (2) takes the value of one if a household made an install at any time during the field experiment. Most of the right-hand side variables are defined as in the IHEA regression in equation (1): the variable $1\left\{\right.$ Any Letter $\left._{i}\right\}$ takes on a value of one if a household

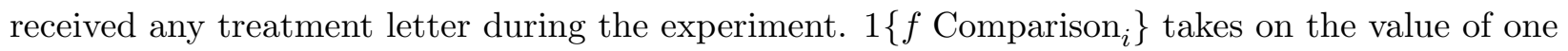
if a household received any letter with framing $f$ during the experiment. The subsidy indicators denote households receiving each of the subsidy levels. Finally, $\omega_{w}$ are wave fixed effects, as before.

We make one alteration and one addition to the right-hand side variables in equation (1). First, we introduce fixed effects $\eta_{t z}$ capturing features of the particular month in which the install occurred $(t)$ and the particular five-digit zip code $(z)$ where the household is located. ${ }^{25}$ In addition, we introduce $\pi_{m}$ as fixed effects for the number of post-treatment months $m \in\{1,2, \ldots, 12\}$ that household $i$ had in which to get an install. Together with the wave fixed effects, these $\pi_{m}$ control for the variation induced by differential timing of treatment letters.

While the coefficient $\alpha$ describes the average probability, for a particular subgroup, of making a durable good purchase over the course of the field experiment, the coefficients $\gamma, \beta_{f}, \delta_{1}$, and $\delta_{2}$

\footnotetext{
${ }^{24}$ We've estimated alternative specifications in which we don't collapse to a cross section and also define installs by treated households in more and less restricted ways. All specifications give very similar results and are available from the authors upon request.

${ }^{25}$ This is in contrast to the set of fixed effects $\nu_{t z}$ for each audit month and five-digit zip pair in equation (1).
} 
capture the marginal impact of any letter, different frames and different subsidy treatments on the unconditional probability of making an install. We are confident in the quality of our data since any install must occur after an IHEA in order to be eligible for the $\$ 500$ rebate in our study area.

Table 6 reports the estimation results of equation (2). Recall that this specification measures the propensity for a household to get an install over the entire treatment period, which is roughly 12 months. The audit regressions measured the propensity of households to get an audit over only two months. As a result, the point estimates measure IHEAs and installs at different time scales (two versus twelve months). Further, before we include various controls for post-treatment months, month-of-year-zip, etc. the results aren’t directly comparable. In the raw data we observe roughly $67 \%$ of households scheduling an audit eventually getting an install.

As with the IHEA regressions, we focus on our preferred specifications in columns 1 and 2 . In the first column without controls, there is a highly significant and negative treatment effect of receiving a letter on getting an install. However, no marginal effects are statistically significant. The point estimate for the treatment effect for receiving any letter is just over $50 \%$ of the point estimate for install averages over the entire sample (.0016 versus .0028). This is consistent with the raw data for install probabilities conditional on audits: for control households about $66 \%$ of IHEA households made an install. The install rate for treatment households who scheduled an audit was roughly $33 \%$. We investigate these conditional installation results further below.

The significance of the Any Letter coefficient but insignificance of the marginal impacts of comparisons and subsidies can be explained straightforwardly as a power issue in column 1. Recall that IHEAs significantly increased in the expenditure and $\mathrm{kWh}$ comparisons above. However, given low installation rates of treated households it is feasible that marginal impacts are not pronounced enough to be significant without adding additional controls.

The underpowered explanation for column 1 is supported by results from column 2 which add 
the full set of fixed effects. In that column, the first important result is that there is no negative impact of Any Letter on installations but there is for $\mathrm{kWh}$ and expenditure Comparisons. This implies households who are "nudged" are less likely to make an install than un-nudged households despite them being more likely to have an IHEA. This asymmetry in search and purchase behavior is not present in the impacts of subsidies: we find no statistically significant impact of receiving subsidies on install probabilities. The subsidy estimates are imprecisely estimated zeroes with point estimates an order of magnitude lower than the comparison estimates. This is informative since the coefficient on the $\$ 50$ subsidy indicator was positive and statistically significant at the $5 \%$ level in the IHEA regression. As before, we are cautious to interpret columns 3-6 due to power concerns but note the broad patterns are shared in those columns.

The unconditional results show that while both nudges and subsidies are effective at increasing IHEA, the subsequent behavior of treated households is different. Social comparison treatments are not effective for increasing installs in our experiment but subsidized households do not install in a significantly different way than households in the control group. This is consistent with nudged households having a lower marginal value of installs than households that select to make an installation on their own. Yet we note that there are a variety of other channels that could be at play.

We investigate treatment's effect on installs further by restricting the sample to only households who made scheduled audits in our sample and re-estimating equation (2). Trimming the sample in this way changes the interpretation of the coefficients $\gamma, \beta_{f}, \delta_{1}$, and $\delta_{2}$. In this specification they are the average differences across treatment conditions in propensity to purchase a durable good conditional on a household having scheduled an IHEA. Significant coefficients indicate that households induced into search behavior by treatment are significantly different in their subsequent purchase behavior than households who self-select into search. 
Table 7 shows the results of the conditional install regressions. Due to the very small sample size, we view column 1 as the preferred specification. The estimated constant term in the first column represents the probability $(67.7 \%)$ a control household makes any installation after an IHEA. Households induced into having an IHEA by $\mathrm{kWh}$ and expenditure comparisons were less likely to make any installation than the control group of untreated households who self-selected into making an installation. There is no statistically significant impact on either subsidy level although point estimates are negative. Adding fixed effects in column two confirms much of the findings of column 1 despite the small sample size. Thus, the general asymmetry across nudges and dollars is preserved vis-a-vis installations.

These purchase results, both unconditional (Table 6) and conditional (Table 7) are somewhat surprising: the same kWh and expenditure comparisons which led to a significant increase in search led to a significant decrease in purchase behavior. There are a few possible candidate explanations, some more plausible than others. First, consider who comprises the set of people eligible to be in the treatment group: all households who had not scheduled an IHEA or made an install prior to the our randomization of treatment status. As a result, they are the set of households least likely, in some sense, to benefit from getting IHEA/install given that the IHEA/install program predated our field experiment. However, the fact that these comparison effects are net of the pure information treatment effect suggests that our result is not merely a function of the marginal household being entirely inelastic. Further, subsidies induce households to audit and install behavior at a rate statistically indistinguishable from the control group.

An alternative take on this result is that there is a fundamental discrepancy in what causes search behavior and what causes purchase behavior. The marginal person induced to search by an expenditure comparison could be very different from the marginal person who is induced to purchase conditional on the outcome of that search behavior (e.g., the information revealed in the 
IHEA itself). For example, if the mechanism behind increased search is normative guilt, that guilt could be alleviated by the IHEA. To the extent that such guilt is concentrated among households that are least elastic on the purchase margin, such a "nudged" household could be less likely to even consider making a purchase after an IHEA since they are simply focusing on the social norm during an IHEA. ${ }^{26}$

There are myriad other explanations. Our design does not allow us to identify the precise mechanism at play. More research in the spirit of Allcott and Kessler (2015) would be useful in understanding "nudges" more precisely along different margins. Our findings highlight, though, that marginal consumers responding to non-pecuniary signals in search can be different than the marginal consumer responding to pecuniary signals in search when we investigate the purchase dimension. This is broadly consistent with other findings that even within the same behavioral margin the impact of non-pecuniary signals can vary (Costa and Kahn, 2013; Gromet et al., 2013). In this way it is in some ways unsurprising, but important for policy, that we find evidence that nudges can be very effective at inducing some economic behaviors but not others.

\section{Discussion}

We find that non-pecuniary signals in our experiment significantly increased search: households that received $\mathrm{kWh}$ and expenditure comparisons were significantly more likely to schedule IHEAs. Comparing that to the point estimate for the treatment effect due to subsidies, it amounts to a subsidy of the IHEA price of $\$ 35-\$ 50$, although the price effect is not statistically significant. However, for purchase behavior we find largely the opposite result: conditional on getting an IHEA and unconditionally, subjects in the expenditure and kWh comparison treatments were significantly

\footnotetext{
${ }^{26}$ Similarly, someone clicking on an ad for a product that they were referred to by a friend may simply prefer to see what their friend suggested rather than even consider purchasing the good.
} 
less likely to make an installation than control households. There is no such divergence in direction of effect for IHEA subsidies.

We urge caution in generalizing our results as we study a very specific type of non-pecuniary information (e.g., comparisons) in only a single scenario. While our results are novel, it is unclear exactly how portable the results of our non-pecuniary signal are to other types of advertising. Even other types of audit programs, for example one that provide a higher level of support to households considering making energy-efficiency installations, could experience different returns to non-pecuniary information. As a result, further research is needed since ours is a single field experiment in a single area. To that end, we found that the content of the non-pecuniary signal matters and simple messages about the existence of the program had little to no effect on search nor purchase. ${ }^{27}$

There are other important implications as well. Consistent with the priming literature, signal framing matters for microeconomic decision-making like search behavior (Chen and Li, 2009; Chen et al., 2010). We find that the "nudges" which have been shown to induce changes in electricity use (e.g., the intensive margin) are not the same nudges that induce longer-lived changes through expensive durable goods purchases (Allcott, 2011; Costa and Kahn, 2013; Ferraro and Price, 2013; Ito et al., 2013; Schultz et al., 2007). This is not to say that the effect of nudges on the intensive margin can't be long-lived through habit formation or some other mechanism (Brent et al., 2015). As a result, understanding who is the marginal consumer for "nudges" and in what way they are marginal will require additional theoretical understanding of the mechanisms at play with different

\footnotetext{
${ }^{27}$ While we've focused on the private good market implications of our research, there are also public good implications. Different federal, state and local policies attempt to correct market failure by establishing or completing markets. Take the example of healthcare.gov as an online marketplace for U.S. consumers to shop for health insurance: much of the literature focuses on the effect of increased medical care on consumer welfare. We inform a complementary question: if healthcare.gov is the solution to a market failure, are there effective non-pecuniary strategies to increase search in addition to enrollment? Further, our results serve as caution against the assumption that strategies effective at increasing search necessarily increase subsequent purchase.
} 
forms of non-pecuniary signals.

Our findings, while only a single study, suggest that additional research on the mechanisms behind non-pecuniary signals' effects on different but related dimensions of human behavior would be valuable. The asymmetric effect of different frames offers suggestive evidence about the channel determining increases in search behavior: privately-framed comparisons (kWh and expenditures), rather than comparisons highlighting a public good aspect $\left(\mathrm{CO}_{2}\right)$ or "pure information," affected search in our context. This result has implications for the channel through which comparisons may operate. Our results are consistent with both 1) a social norm channel and 2) an information-based channel in which households infer information about what their use could be based upon averages in their local area. Finally, given that we provided the same information framed differently, it also provides evidence of bounded rationality. Nonetheless, it is not clear what caused households to be "nudged" into IHEAs by kWh and expenditure comparisons. Further work is needed to identify the precise mechanism. In particular, our findings motivate future work to understand exactly who is marginal for different kinds of non-pecuniary signals that affect various economic decisions (e.g., search, purchase, etc.). 


\section{References}

Allcott, H. and T. Rodgers, "The Short-Run and Long-Run Effects of Behavioral Interventions: Experimental Evidence from Energy Conservation," American Economic Review, 2014, 104 (10), 3003-3037.

Allcott, Hunt, "Social Norms and Energy Conservation," Journal of Public Economics, 2011, 95 (9), 1082-1095.

_ and Judd B. Kessler, "The Welfare Effect of Nudges," NBER Working Paper 21671, 2015.

- and Michael Greenstone, "Is There an Energy Efficiency Gap?," Journal of Economic Perspectives, 2012, 26 (1), 3-28.

_ and _ , "Measuring the Welfare Effects of Energy Efficiency Programs," Working paper, 2015.

Attari, Shahzeen Z., Michael L. DeKay, Cliff I. Davidson, and Wändi Bruine de Bruin, "Public perceptions of energy consumption and savings," Proceedings of the National Academy of Sciences, 2010, 107 (37), 16054-16059.

Bernedo, María, Paul Ferraro, and Michael Price, "The Persistent Impacts of Norm-Based Messaging and Their Implications for Water Conservation," Journal of Consumer Policy, September 2014, $37(3), 437-452$.

Beshears, John, James J. Choi, David Laibson, Brigitte C. Madrian, and Katherine L. Milkman, "The Effect of Providing Peer Information on Retirement Savings Decisions," Journal of Finance, 2015, 70 (3), 1161-1201.

Brent, Daniel A, Joseph H Cook, and Skylar Olsen, "Social Comparisons, Household Water Use, and Participation in Utility Conservation Programs: Evidence from Three Randomized 
Trials," Journal of the Association of Environmental and Resource Economists, 2015, 2 (4), 597-627.

Chen, Y. and S. Li, "Group Identity and Social Preferences," American Economic Review, 2009, 99 (1), 431-457.

_, F.M. Harper, and J. Konstan S. Li, "Social Comparisons and Contributions to Online Communities: A Field Experiment on MovieLens," American Economic Review, 2010, 100 (4), $1358-1398$.

Cialdini, Robert B, Linda J Demaine, Brad J Sagarin, Daniel W Barrett, Kelton Rhoads, and Patricia L Winter, "Managing social norms for persuasive impact," Social influence, 2006, 1 (1), 3-15.

Costa, Dora L and Matthew E Kahn, "Energy conservation nudges and environmentalist ideology: Evidence from a randomized residential electricity field experiment," Journal of the European Economic Association, 2013, 11 (3), 680-702.

DellaVigna, Stefano, John A. List List, and Ulrike Malmendier, "Testing for Altruism and Social Pressure in Charitable Giving," Quarterly Journal of Economics, 2012, 127 (1), 1-56.

_, John A. List, Ulrike Malmendier, and Gautam Rao, "Voting to Tell Others," Review of Economics Studies, 2016, forthcoming.

Dolan, Paul and Robert Metcalfe, "Neighbors, knowledge, and nuggets: Two natural field experiments on the role of incentives on energy conservation," University of Chicago Working paper, 2015. 
Duflo, Emmanuel Saez Esther, "The Role of Information and Social Interactions in Retirement Plan Decisions: Evidence from a Randomized Experiment," The Quarterly Journal of Economics, $2003,118(3), 815-842$.

Edo, P. and B. Szentes, "The Price of Advice," The RAND Journal of Economics, 2007, 38 (4), $865-880$.

Ferraro, Paul and Michael Price, "Using Non-Pecuniary Strategies to Influence Behavior: Evidence from a Large Scale Field Expirement," Review of Economics and Statistics, 2013, 95 (1), 64-73.

Ferraro, Paul J., Juan Jose Miranda, and Michael K. Price, "The Persistence of Treatment Effects with Norm-Based Policy Instruments: Evidence from a Randomized Environmental Policy Experiment," American Economic Review, May 2011, 101 (3), 318-22.

Fowlie, Meredith, Michael Greenstone, and Catherine Wolfram, "Are the non-monetary costs of energy efficiency investments large? Understanding low take-up of a free energy efficiency program," The American Economic Review, 2015, 105 (5), 201-204.

Frey, Bruno S. and Stephan Meier, "Social Comparisons and Pro-social Behavior: Testing \&quot;Conditional Cooperation\&quot; in a Field Experiment," American Economic Review, December 2004, 94 (5), 1717-1722.

Gilbert, B., J. LaRiviere, and K. Novan, "Incentives and Additionality in Energy Efficiency Subsidies," Association of Environmental and Resource Economists 4th Annual Summer Conerence, 2015, June. 
Gromet, Dena M, Howard Kunreuther, and Richard P Larrick, "Political ideology affects energy-efficiency attitudes and choices," Proceedings of the National Academy of Sciences, 2013, 110 (23), 9314-9319.

Ito, Koichiro, Takanori Ida, and Makoto Tanaka, "Using Dynamic Electricity Pricing to Address Energy Crises Evidence from Randomized Field Experiments," Boston University Working Paper, 2013.

Lewis, R. and J. Rao, "The Unfavorable Economics of Measuring the Returns to Adverising," Quarterly Journal of Economics, 2015, forthcoming.

McKinsey, "Unlocking energy efficiency in the US economy," McKinsey and Company, 2009.

Palmer, Karen and Margaret Walls, "Limited Attention and the Residential Energy Efficiency Gap," The American Economic Review, 2015, 105 (5), 192-195.

Pitchik, C. and A. Schotter, "Honesty in a Model of Strategic Information Transmission," The American Economic Review, 1987, 77 (5), 1032-1036.

Rothschild, M., "A One-Armed Bandit Model of Search Behavior," Journal of Economic Theory, 1974, 9, 185-202.

Schultz, P Wesley, Jessica M Nolan, Robert B Cialdini, Noah J Goldstein, and Vladas Griskevicius, "The constructive, destructive, and reconstructive power of social norms," Psychological science, 2007, 18 (5), 429-434.

Schutlz, PW, JM Nolan, RB Cialdini, NJ Goldstein, and V Griskevicius, "The Constructive, Destructive, and Reconstructive Power of Social Norms," Psychological Science, 2007, $18(5), 429-434$. 
Shang, Jen and Rachel Croson, "A Field Experiment in Charitable Contribution: The Impact of Social Information on the Voluntary Provision of Public Goods," The Economic Journal, 2009, 119 (540), 1422-1439.

Trope, Yaacov and Nira Liberman, "Construal-Level Theory of Psychological Distance," Psychological Review, 2010, 117 (2), 440-463.

Wichman, Casey, Laura Taylor, and Roger von Haefen, "Conservation policies: Who responds to price and who responds to prescription?," Journal of Environmental Economics and Management, 2016, 79, 114-134. 
Figure 1: Decision Tree for Field Experiment

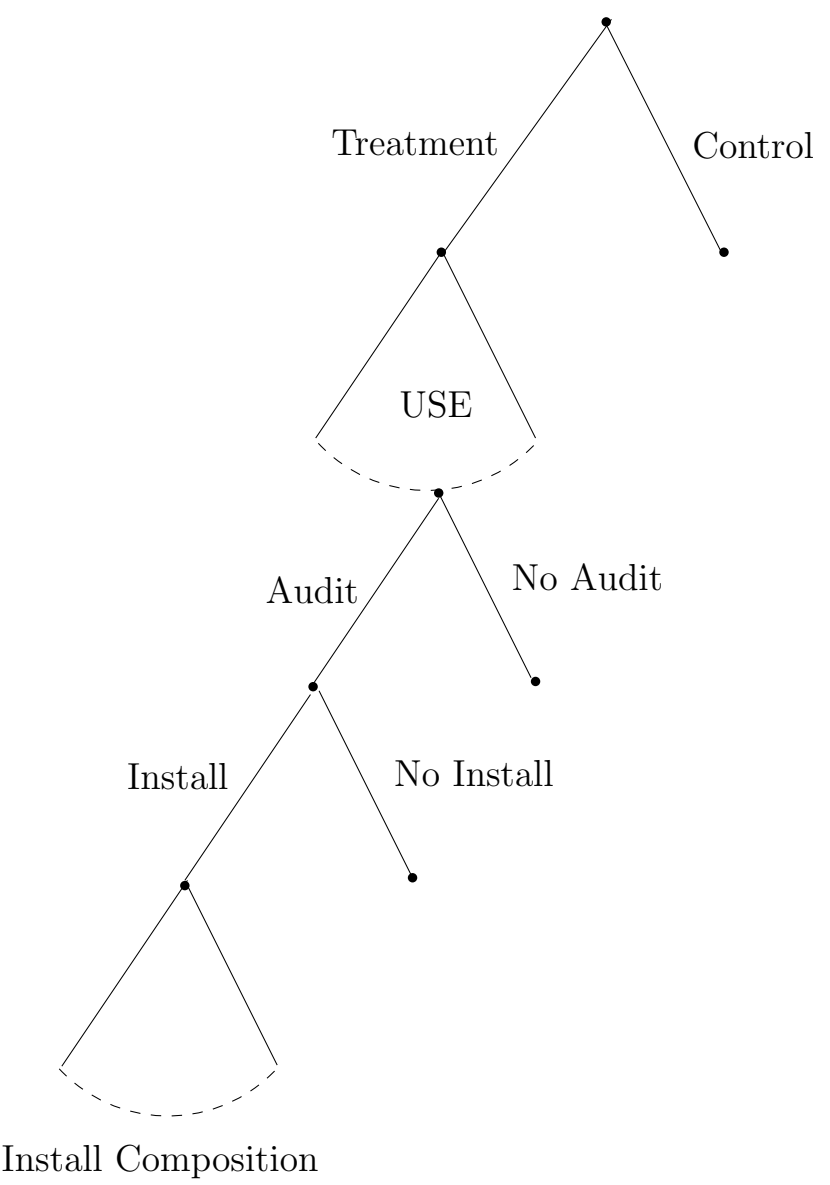

Note: Control households have same access to same decisions over every node. 
Figure 2: Timing of Waves Gantt Chart

$12 / 1 / 2012$

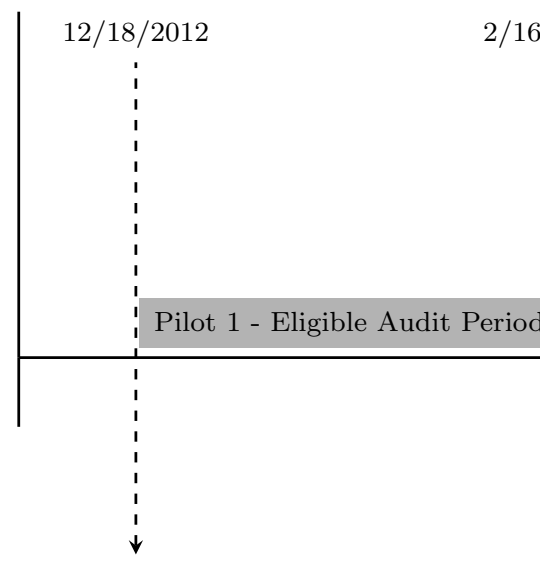

$$
\text { Pilot } 1
$$

First Letter Sent
$2 / 16 / 2013$

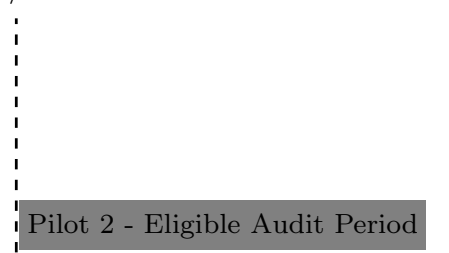

Pilot 2 - Eligible Audit Period

\section{d}

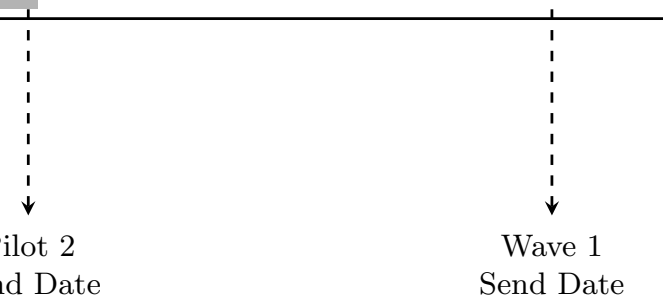



$10 / 1 / 2013$



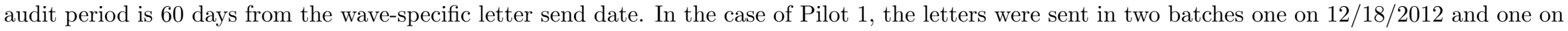

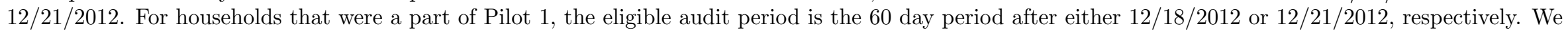
omit the $12 / 21 / 2012$ batch from the Figure to simplify the presentation. 
Figure 3: Variation in Letter Content

We thought that you might be interested in the following information about your energy usage last year:

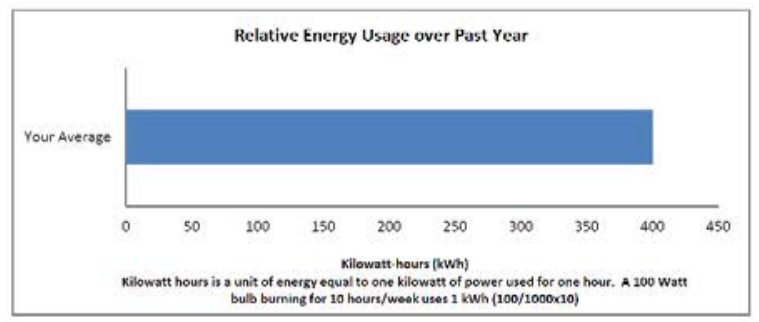

Your average energy consumption over the past year: $400 \mathrm{kWh}$

We thought that you might be interested in the following information about the $\mathrm{CO} 2$ created through your energy

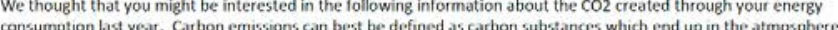
Such gases are produced by many things including cars, industrial plants and electricty production

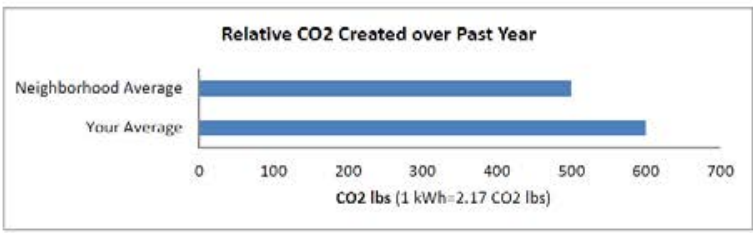

Your Energy Use

tocal Area Homes' Energy Use

$500 \mathrm{kWh}$ created 1,085 Ibs of $\mathrm{CO} 2$ emissions: 600 kWh created 1,302 lbs of $\mathrm{CO} 2$ emissions

You produced $20 \%$ more $\mathrm{CO} 2$ emissions than other area homes.
We thought that you might be interested in the following intormation about your energy usage last year:

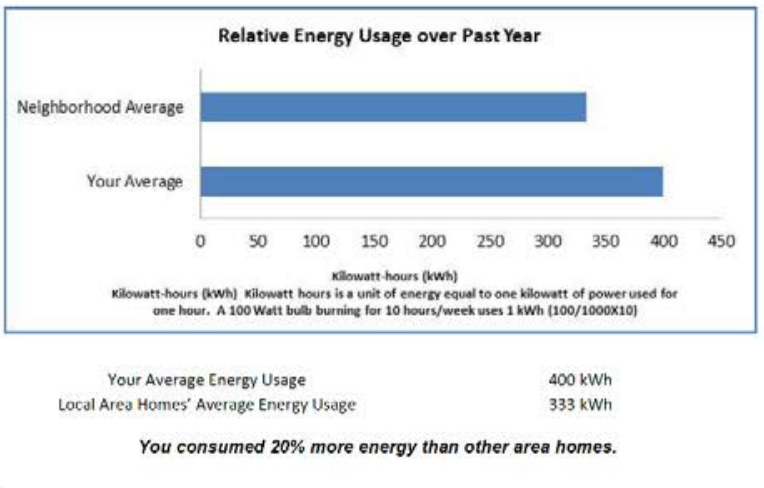

We thought that you might be interested in the following information about your energy bills last year:

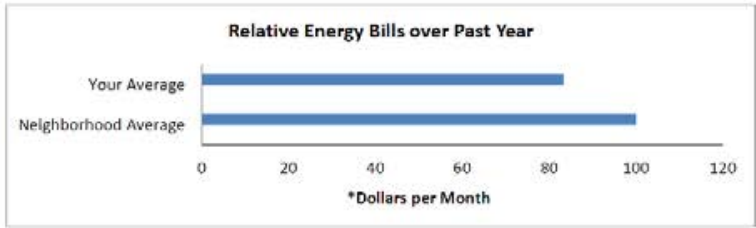

Doallars per month caiculated ot S.XX per $k$ WW



You spent $28 \%$ more dollars than other area homes.

Note: The top left panel corresponds to the No Comparison treatment letters. The top right panel corresponds to the $\mathrm{kWh}$ Comparison letters. The bottom left panel corresponds to the $\mathrm{CO}_{2}$ Comparison letters. Finally, the bottom right panel corresponds to the $\$$ Comparison (i.e., expenditure) letters. 
Figure 4: Timing of Installs Relative to Audits

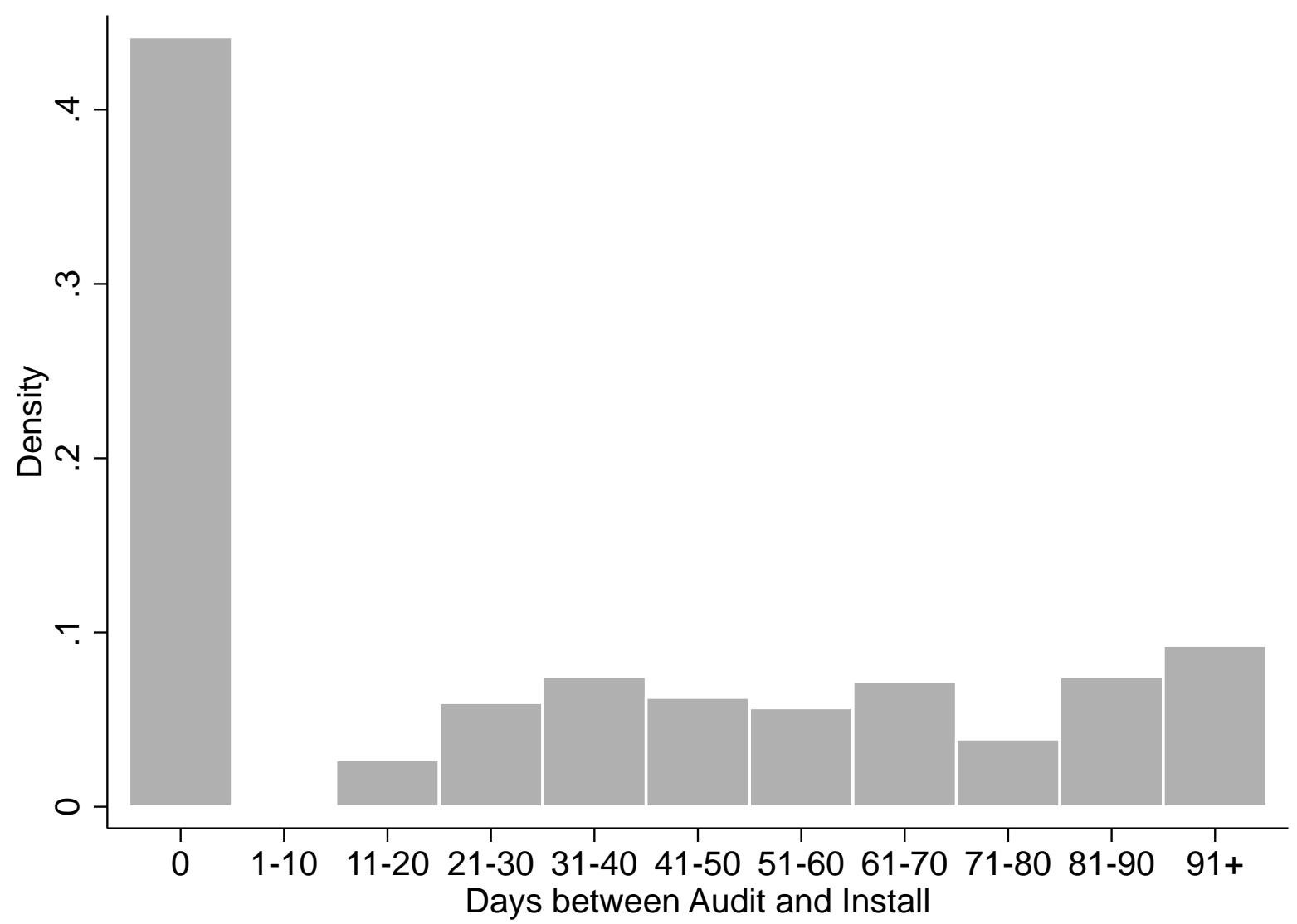

Note: Data include all installations in the data set. All installations are preceeded by an audit. 
Table 1: Treatments Used in Field Experiment and Covariate Balance

\begin{tabular}{llcccc}
\hline & & No Subsidy & $\$ 20$ Subsidy & $\$ 50$ Subsidy & All Subsidy Levels \\
\hline \multirow{2}{*}{ No Comparison } & Sample Size & 3,923 & 7,617 & 3,694 & 15,234 \\
& Mean Pre-Treatment Use (kWh) & $1,326.90$ & $1,322.06$ & $1,312.30$ & $1,320.94$ \\
& & $(9.33)$ & $(6.76)$ & $(9.71)$ & $(4.77)$ \\
\multirow{2}{*}{ kWh Comparison } & Sample Size & 3,476 & 6,893 & 3,374 & 13,743 \\
& Mean Pre-Treatment Use (kWh) & $1,316.45$ & $1,319.69$ & $1,327.60$ & $1,320.81$ \\
& & $(10.25)$ & $(7.09)$ & $(10.23)$ & $(5.07)$ \\
\multirow{5}{*}{ \$ Comparison } & 3,737 & 7,736 & 3,756 & 15,229 \\
& Sample Size & $1,323.17$ & $1,318.91$ & $1,325.74$ & $1,321.64$ \\
& Mean Pre-Treatment Use $(\mathrm{kWh})$ & $(9.88)$ & $(6.75)$ & $(10.28)$ & $(4.91)$ \\
& & 1,632 & 3,347 & 1,612 & 6,591 \\
CO ${ }_{2}$ Comparison & Sample Size & $1,317.90$ & $1,317.50$ & $1,330.52$ & $1,320.79$ \\
& Mean Pre-Treatment Use $(\mathrm{kWh})$ & $(14.48)$ & $(10.59)$ & $(15.07)$ & $(7.44)$ \\
\hline \multirow{2}{*}{ All Letter Types } & Sample Size & 12,768 & 25,593 & 12,436 & 50,797 \\
& Mean Pre-Treatment Use $(\mathrm{kWh})$ & $1,321.81$ & $1,319.87$ & $1,322.87$ & $1,321.09$ \\
& & $(5.27)$ & $(3.71)$ & $(5.43)$ & $(2.65)$ \\
\hline
\end{tabular}

Note: In the No Comparison treatment row, households are told only their own use measured in kWhs. Elements of each cell indicate individual treatments, whereas numbers in parenthesis record the number of households in that treatment cell. There was also a large control group consisting of a within-wave control group and a super-control group never assigned to a wave. The size of the super control group was 49,751 households, with a mean pre-treatment use of 1,319.56 kWh and standard error of 2.69. 
Table 2: Sample Size by Wave and Treatment Type

\begin{tabular}{|c|c|c|c|c|c|c|}
\hline & $\begin{array}{c}\text { Pilot } 1 \\
\text { Dec } 18-21,2012\end{array}$ & $\begin{array}{c}\text { Pilot } 2 \\
\text { Feb 16, } 2013\end{array}$ & $\begin{array}{c}\text { Wave } 1 \\
\text { May 3, } 2013\end{array}$ & $\begin{array}{c}\text { Wave } 2 \\
\text { Jul 1, } 2013\end{array}$ & $\begin{array}{c}\text { Wave } 3 \\
\text { Aug } 12,2013\end{array}$ & Total \\
\hline Within-Wave Control & 632 & 522 & 2,598 & 2,726 & 3,089 & 9,567 \\
\hline No Comparison - No Subsidy & 280 & 304 & 1,075 & 1,097 & 1,167 & 3,923 \\
\hline kWh Comparison - No Subsidy & 224 & 0 & 1,121 & 1,019 & 1,112 & 3,476 \\
\hline \$ Comparison - No Subsidy & 253 & 298 & 1,046 & 1,074 & 1,066 & 3,737 \\
\hline $\mathrm{CO}_{2}$ Comparison - No Subsidy & 209 & 333 & 0 & 0 & 1,090 & 1,632 \\
\hline No Comparison - $\$ 20$ Subsidy & 452 & 652 & 2,188 & 2,189 & 2,136 & 7,617 \\
\hline kWh Comparison - $\$ 20$ Subsidy & 423 & 0 & 2,239 & 2,097 & 2,134 & 6,893 \\
\hline$\$$ Comparison - $\$ 20$ Subsidy & 564 & 646 & 2,157 & 2,095 & 2,274 & 7,736 \\
\hline $\mathrm{CO}_{2}$ Comparison - $\$ 20$ Subsidy & 493 & 621 & 0 & 0 & 2,233 & 3,347 \\
\hline No Comparison - $\$ 50$ Subsidy & 192 & 332 & 1,051 & 1,033 & 1,086 & 3,694 \\
\hline kWh Comparison - $\$ 50$ Subsidy & 196 & 0 & 1,055 & 997 & 1,126 & 3,374 \\
\hline$\$$ Comparison - $\$ 50$ Subsidy & 205 & 288 & 1,039 & 1,139 & 1,085 & 3,756 \\
\hline $\mathrm{CO}_{2}$ Comparison - $\$ 50$ Subsidy & 204 & 308 & 0 & 0 & 1,100 & 1,612 \\
\hline Total & 4,327 & 4,304 & 15,569 & 15,466 & 20,698 & 60,364 \\
\hline
\end{tabular}

Note: Each column reports the sample size for a particular wave of the experiment and each row reports the sample size for a treatment type. The experiment also included a super-control of 40,184 households which were not assigned to any wave. Date represents the drop date for the mailing of the treatment letters in that wave. Any cells with 0 households indicate a letter type (either kWh Comparison or $\mathrm{CO}_{2}$ Comparison) that was not included in that particular wave. 
Table 3: Unadjusted IHEA Uptake Rates During Experiment by Treatment Type

\begin{tabular}{lcccc}
\hline & No Subsidy & $\$ 20$ Subsidy & $\$ 50$ Subsidy & Total \\
\hline No Comparison & 0.0008 & 0.0012 & 0.0014 & 0.0011 \\
kWh Comparison & 0.0021 & 0.0022 & 0.0036 & 0.0025 \\
$\$$ Comparison & 0.0016 & 0.0032 & 0.0022 & 0.0025 \\
$\mathrm{CO}_{2}$ Comparison & 0.0006 & 0.0018 & 0.0006 & 0.0012 \\
Total & 0.0014 & 0.0021 & 0.0021 & 0.0019 \\
\hline
\end{tabular}

Note: Each cell in the table reports the average 60-day (from the date the treatment letters were sent out) uptake rate of IHEAs by households in that particular treatment cell. Omitted from the table is the average 60-day IHEA uptake rate for the control group (which was not sent any letter) which is .0011. Throughout, we exclude households with IHEAs prior to treatment or after the end of the observation period (1,548 households excluded, in total). 
Table 4: Impact of Treatment Letter and Subsidy on IHEA Uptake Rates

\begin{tabular}{|c|c|c|c|c|c|c|}
\hline & 1 & 2 & 3 & 4 & 5 & 6 \\
\hline Any Letter & $\begin{array}{l}-0.0005 \\
(0.0004)\end{array}$ & $\begin{array}{l}-0.0003 \\
(0.0002)\end{array}$ & $\begin{array}{l}-0.0001 \\
(0.0003)\end{array}$ & $\begin{array}{l}-0.0000 \\
(0.0002)\end{array}$ & $\begin{array}{l}-0.0002 \\
(0.0003)\end{array}$ & $\begin{array}{l}-0.0001 \\
(0.0002)\end{array}$ \\
\hline kWh Comparison & $\begin{array}{c}0.0014^{* * *} \\
(0.0005)\end{array}$ & $\begin{array}{l}0.0004^{* *} \\
(0.0002)\end{array}$ & $\begin{array}{l}-0.0001 \\
(0.0003)\end{array}$ & $\begin{array}{l}-0.0000 \\
(0.0001)\end{array}$ & $\begin{array}{l}-0.0000 \\
(0.0003)\end{array}$ & $\begin{array}{c}0.0000 \\
(0.0001)\end{array}$ \\
\hline$\$$ Comparison & $\begin{array}{c}0.0014^{* * *} \\
(0.0005)\end{array}$ & $\begin{array}{l}0.0005^{* *} \\
(0.0002)\end{array}$ & $\begin{array}{c}0.0001 \\
(0.0003)\end{array}$ & $\begin{array}{l}0.0005^{* *} \\
(0.0002)\end{array}$ & $\begin{array}{c}0.0001 \\
(0.0003)\end{array}$ & $\begin{array}{c}0.0008^{* * * *} \\
(0.0003)\end{array}$ \\
\hline $\mathrm{CO}_{2}$ Comparison & $\begin{array}{c}0.0001 \\
(0.0005)\end{array}$ & $\begin{array}{c}0.0003 \\
(0.0002)\end{array}$ & $\begin{array}{c}0.0001 \\
(0.0003)\end{array}$ & $\begin{array}{c}0.0001 \\
(0.0002)\end{array}$ & $\begin{array}{c}0.0001 \\
(0.0003)\end{array}$ & $\begin{array}{c}0.0001 \\
(0.0002)\end{array}$ \\
\hline$\$ 20$ Subsidy & $\begin{array}{l}0.0008^{*} \\
(0.0004)\end{array}$ & $\begin{array}{c}0.0002 \\
(0.0002)\end{array}$ & $\begin{array}{c}0.0002 \\
(0.0002)\end{array}$ & $\begin{array}{l}-0.0002 \\
(0.0002)\end{array}$ & $\begin{array}{c}0.0004^{* *} \\
(0.0002)\end{array}$ & $\begin{array}{l}-0.0002 \\
(0.0002)\end{array}$ \\
\hline$\$ 50$ Subsidy & $\begin{array}{c}0.0008 \\
(0.0005)\end{array}$ & $\begin{array}{l}0.0005^{* *} \\
(0.0002)\end{array}$ & $\begin{array}{c}0.0001 \\
(0.0003)\end{array}$ & $\begin{array}{c}0.0002 \\
(0.0002)\end{array}$ & $\begin{array}{c}0.0002 \\
(0.0002)\end{array}$ & $\begin{array}{c}0.0002 \\
(0.0002)\end{array}$ \\
\hline Constant & $\begin{array}{c}0.0011^{* * *} \\
(0.0001)\end{array}$ & & & & & \\
\hline Audit Month-Year by ZIP5 & No & Yes & Yes & Yes & Yes & Yes \\
\hline Wave & No & Yes & Yes & Yes & Yes & Yes \\
\hline Sample & $\begin{array}{c}\text { Full } \\
\text { Sample }\end{array}$ & $\begin{array}{c}\text { Full } \\
\text { Sample }\end{array}$ & $\begin{array}{c}\text { Above } \\
\text { Local Median }\end{array}$ & $\begin{array}{c}\text { Below } \\
\text { Local Median }\end{array}$ & $\begin{array}{c}\text { Above } \\
\text { MSA Median }\end{array}$ & $\begin{array}{c}\text { Below } \\
\text { MSA Median }\end{array}$ \\
\hline$R^{2}$ & 0.0003 & 0.6950 & 0.7558 & 0.7283 & 0.7478 & 0.7251 \\
\hline $\mathrm{N}$ & 99,000 & 98,952 & 50,426 & 38,978 & 50,859 & 38,253 \\
\hline
\end{tabular}

Note: Dependent variable is an indicator for households that completed an IHEA within 60 days of receiving a treatment letter (or be part of the control group). Any Letter is an indicator for receiving any of the social comparison letters or an information-only letter during the study. $\mathrm{kWh}$ Comparison is an indicator for receiving a social comparison letter with units all in $\mathrm{kWh}$ during the study. $\$$ Comparison is an indicator for receiving a social comparison letter with units all in dollars during the study. $\mathrm{CO}_{2}$ Comparison is an indicator for receiving a social comparison letter with units all in pounds of $\mathrm{CO}_{2}$ during the study. Columns 1 and 2 are estimated on the full sample of households. Column 3 is estimated on the restricted sample of households with average pre-experiment use above the median in their local area. Column 4 is estimated on the restricted sample of households with average pre-experiment use below the median in their local area. Columns 5 and 6 reproduce Columns 3 and 4 (respectively), but use MSA instead of local area Column 1 includes no controls. Columns 2-6 include controls for the wave of the experiment as well as month-year-ZIP5 level using the IHEA date. All standard errors are robust to heteroskedasticity. We exclude households with IHEAs prior to treatment or after the end of the observation period (a total of 1,548 households). Neither above- nor below-median models include households within the median (fifth) decile.

$* * *$ significant at the $1 \%$ level, $* *$ significant at the $5 \%$ level, $*$ significant at the $10 \%$ level. 
Table 5: Unadjusted Time-to-Install (from Audit Date) by Treatment

\begin{tabular}{lcccc}
\hline & No Subsidy & $\$ 20$ Subsidy & $\$ 50$ Subsidy & Total \\
\hline No Comparison & 44.33 & 40.75 & 13.40 & 37.68 \\
kWh Comparison & 52.62 & 14.47 & 6.42 & 19.82 \\
$\$$ Comparison & 25.57 & 26.00 & 17.00 & 23.55 \\
$\mathrm{CO}_{2}$ Comparison & 39.50 & 20.56 & 224.00 & 40.67 \\
Total & 41.46 & 26.35 & 19.00 & 27.58 \\
\hline
\end{tabular}

Note: Each cell reports the average time-to-install (among installs within that cell) from the date of the audit. Control group mean post-audit time-to-install is roughly 41.46 days. Certain cells in the table only have 1 or 2 observations. 
Table 6: Impact of Treatment Letter and Subsidy on Installs Ever

\begin{tabular}{|c|c|c|c|c|c|c|}
\hline & 1 & 2 & 3 & 4 & 5 & 6 \\
\hline Any Letter & $\begin{array}{c}-0.0016^{* * *} \\
(0.0004)\end{array}$ & $\begin{array}{l}-0.0002 \\
(0.0002)\end{array}$ & $\begin{array}{c}0.0001 \\
(0.0003)\end{array}$ & $\begin{array}{l}-0.0003 \\
(0.0002)\end{array}$ & $\begin{array}{c}0.0000 \\
(0.0003)\end{array}$ & $\begin{array}{l}-0.0002 \\
(0.0002)\end{array}$ \\
\hline kWh Comparison & $\begin{array}{l}-0.0005 \\
(0.0004)\end{array}$ & $\begin{array}{c}-0.0003^{*} \\
(0.0002)\end{array}$ & $\begin{array}{c}-0.0004 \\
(0.0003)\end{array}$ & $\begin{array}{c}-0.0003 \\
(0.0002)\end{array}$ & $\begin{array}{c}-0.0003 \\
(0.0003)\end{array}$ & $\begin{array}{l}-0.0004 \\
(0.0002)\end{array}$ \\
\hline$\$$ Comparison & $\begin{array}{l}-0.0002 \\
(0.0004)\end{array}$ & $\begin{array}{c}-0.0005^{* *} \\
(0.0002)\end{array}$ & $\begin{array}{c}-0.0008^{* * *} \\
(0.0003)\end{array}$ & $\begin{array}{c}0.0002 \\
(0.0002)\end{array}$ & $\begin{array}{c}-0.0007^{* *} \\
(0.0003)\end{array}$ & $\begin{array}{l}-0.0000 \\
(0.0002)\end{array}$ \\
\hline $\mathrm{CO}_{2}$ Comparison & $\begin{array}{l}-0.0003 \\
(0.0005)\end{array}$ & $\begin{array}{l}-0.0000 \\
(0.0002)\end{array}$ & $\begin{array}{l}-0.0001 \\
(0.0003)\end{array}$ & $\begin{array}{l}-0.0001 \\
(0.0001)\end{array}$ & $\begin{array}{l}-0.0001 \\
(0.0003)\end{array}$ & $\begin{array}{l}-0.0001 \\
(0.0001)\end{array}$ \\
\hline$\$ 20$ Subsidy & $\begin{array}{c}0.0002 \\
(0.0004)\end{array}$ & $\begin{array}{l}-0.0000 \\
(0.0002)\end{array}$ & $\begin{array}{l}-0.0002 \\
(0.0002)\end{array}$ & $\begin{array}{c}0.0001 \\
(0.0002)\end{array}$ & $\begin{array}{l}-0.0001 \\
(0.0002)\end{array}$ & $\begin{array}{c}0.0000 \\
(0.0002)\end{array}$ \\
\hline$\$ 50$ Subsidy & $\begin{array}{l}-0.0004 \\
(0.0004)\end{array}$ & $\begin{array}{l}-0.0000 \\
(0.0002)\end{array}$ & $\begin{array}{c}0.0001 \\
(0.0002)\end{array}$ & $\begin{array}{l}-0.0000 \\
(0.0002)\end{array}$ & $\begin{array}{c}0.0001 \\
(0.0002)\end{array}$ & $\begin{array}{c}0.0000 \\
(0.0002)\end{array}$ \\
\hline Constant & $\begin{array}{c}0.0028^{* * *} \\
(0.0002)\end{array}$ & & & & & \\
\hline Install Month-Year by ZIP5 & No & Yes & Yes & Yes & Yes & Yes \\
\hline Wave & No & Yes & Yes & Yes & Yes & Yes \\
\hline \# Post-Treatment Months & No & Yes & Yes & Yes & Yes & Yes \\
\hline Sample & $\begin{array}{c}\text { Full } \\
\text { Sample }\end{array}$ & $\begin{array}{c}\text { Full } \\
\text { Sample }\end{array}$ & $\begin{array}{c}\text { Above } \\
\text { Local Median }\end{array}$ & $\begin{array}{c}\text { Below } \\
\text { Local Median }\end{array}$ & $\begin{array}{c}\text { Above } \\
\text { MSA Median }\end{array}$ & $\begin{array}{c}\text { Below } \\
\text { MSA Median }\end{array}$ \\
\hline$R^{2}$ & 0.0005 & 0.7326 & 0.7443 & 0.8833 & 0.7321 & 0.8826 \\
\hline $\mathrm{N}$ & 99,000 & 98,962 & 50,435 & 38,969 & 50,865 & 38,248 \\
\hline
\end{tabular}

Note: Dependent variable is an indicator for households that made 1 or more energy-efficient installations at some point during the experiment and post-treatment. Any Letter is an indicator for receiving any of the social comparison letters or an information-only letter during the study. $\mathrm{kWh}$ Comparison is an indicator for receiving a social comparison letter with units all in $\mathrm{kWh}$ during the study. \$ Comparison is an indicator for receiving a social comparison letter with units all in dollars during the study. $\mathrm{CO}_{2}$ Comparison is an indicator for receiving a social comparison letter with units all in pounds of $\mathrm{CO}_{2}$ during the study. Columns 1 and 2 are estimated on the full sample of households. Column 3 is estimated on the restricted sample of households with average pre-experiment use above the median in their local area. Column 4 is estimated on the restricted sample of households with average pre-experiment use below the median in their local area. Columns 5 and 6 reproduce Columns 3 and 4 (respectively), but use MSA instead of local area. Column 1 includes no controls. To account for differential timing of the treatment letter send dates, Columns 2-6 include controls for the wave of the experiment as well as the number of post-treatment months that each household had to (potentially) respond to treatment. In addition, Columns $2-6$ include fixed effects at the month-year-ZIP5 level using the install date. All standard errors are robust to heteroskedasticity. We exclude households with IHEAs prior to treatment or after the end of the observation period (a total of 1,548 households). Neither above- nor below-median models include households within the median (fifth) decile.

$* * *$ significant at the $1 \%$ level, $* *$ significant at the $5 \%$ level, $*$ significant at the $10 \%$ level. 
Table 7: Impact of Treatment Letter and Subsidy on Installs Ever (Conditional on IHEA)

\begin{tabular}{|c|c|c|c|c|c|c|}
\hline & 1 & 2 & 3 & 4 & 5 & 6 \\
\hline Any Letter & $\begin{array}{l}-0.0819 \\
(0.1221)\end{array}$ & $\begin{array}{c}-0.3235^{* *} \\
(0.1569)\end{array}$ & $\begin{array}{l}-0.3506 \\
(0.2193)\end{array}$ & $\begin{array}{l}-0.3327 \\
(0.2106)\end{array}$ & $\begin{array}{l}-0.3524 \\
(0.2524)\end{array}$ & $\begin{array}{l}-0.5790 \\
(0.3754)\end{array}$ \\
\hline kWh Comparison & $\begin{array}{c}-0.2494^{* *} \\
(0.1111)\end{array}$ & $\begin{array}{l}-0.0739 \\
(0.1218)\end{array}$ & $\begin{array}{l}-0.0871 \\
(0.1493)\end{array}$ & $\begin{array}{c}-0.8092^{* * *} \\
(0.1734)\end{array}$ & $\begin{array}{l}-0.0760 \\
(0.1554)\end{array}$ & $\begin{array}{c}-0.5279^{*} \\
(0.2980)\end{array}$ \\
\hline \$ Comparison & $\begin{array}{c}-0.2009^{*} \\
(0.1089)\end{array}$ & $\begin{array}{l}-0.1179 \\
(0.0996)\end{array}$ & $\begin{array}{c}-0.2324^{* *} \\
(0.1169)\end{array}$ & $\begin{array}{c}0.3230 \\
(0.1949)\end{array}$ & $\begin{array}{l}-0.1976 \\
(0.1288)\end{array}$ & $\begin{array}{c}0.1341 \\
(0.1803)\end{array}$ \\
\hline $\mathrm{CO}_{2}$ Comparison & $\begin{array}{l}-0.0309 \\
(0.1726)\end{array}$ & $\begin{array}{c}0.0122 \\
(0.1473)\end{array}$ & $\begin{array}{l}-0.1391 \\
(0.2682)\end{array}$ & $\begin{array}{c}0.1489 \\
(0.1451)\end{array}$ & $\begin{array}{l}-0.1382 \\
(0.2693)\end{array}$ & $\begin{array}{c}0.1503 \\
(0.1603)\end{array}$ \\
\hline$\$ 20$ Subsidy & $\begin{array}{l}-0.0643 \\
(0.1128)\end{array}$ & $\begin{array}{c}0.0625 \\
(0.1048)\end{array}$ & $\begin{array}{c}0.0637 \\
(0.1644)\end{array}$ & $\begin{array}{l}-0.2515 \\
(0.1507)\end{array}$ & $\begin{array}{c}0.0618 \\
(0.1791)\end{array}$ & $\begin{array}{l}-0.1158 \\
(0.2186)\end{array}$ \\
\hline$\$ 50$ Subsidy & $\begin{array}{l}-0.1871 \\
(0.1266)\end{array}$ & $\begin{array}{l}0.2448^{*} \\
(0.1242)\end{array}$ & $\begin{array}{c}0.2400 \\
(0.1636)\end{array}$ & $\begin{array}{c}0.0656 \\
(0.1607)\end{array}$ & $\begin{array}{c}0.2475 \\
(0.1918)\end{array}$ & $\begin{array}{c}0.2213 \\
(0.3409)\end{array}$ \\
\hline Constant & $\begin{array}{c}0.6766^{* * *} \\
(0.0333)\end{array}$ & & & & & \\
\hline Install Month-Year by ZIP5 & No & Yes & Yes & Yes & Yes & Yes \\
\hline Wave & No & Yes & Yes & Yes & Yes & Yes \\
\hline \# Post-Treatment Months & No & Yes & Yes & Yes & Yes & Yes \\
\hline Sample & $\begin{array}{c}\text { Full } \\
\text { Sample }\end{array}$ & $\begin{array}{c}\text { Full } \\
\text { Sample }\end{array}$ & $\begin{array}{c}\text { Above } \\
\text { Local Median }\end{array}$ & $\begin{array}{c}\text { Below } \\
\text { Local Median }\end{array}$ & $\begin{array}{c}\text { Above } \\
\text { MSA Median }\end{array}$ & $\begin{array}{c}\text { Below } \\
\text { MSA Median }\end{array}$ \\
\hline$R^{2}$ & 0.1215 & 0.5778 & 0.6687 & 0.8625 & 0.6399 & 0.8278 \\
\hline $\mathrm{N}$ & 335 & 297 & 167 & 62 & 162 & 68 \\
\hline
\end{tabular}

Note: All results are conditional on scheduling an IHEA. Dependent variable is an indicator for households that made 1 or more energy-efficient installations at some point during the experiment and post-treatment. Any Letter is an indicator for receiving any of the social comparison letters or an information-only letter during the study. $\mathrm{kWh}$ Comparison is an indicator for receiving a social comparison letter with units all in $\mathrm{kWh}$ during the study. \$ Comparison is an indicator for receiving a social comparison letter with units all in dollars during the study. $\mathrm{CO}_{2}$ Comparison is an indicator for receiving a social comparison letter with units all in pounds of $\mathrm{CO}_{2}$ during the study. Columns 1 and 2 are estimated on the full sample of households. Column 3 is estimated on the restricted sample of households with average pre-experiment use above the median in their local area. Column 4 is estimated on the restricted sample of households with average pre-experiment use below the median in their local area. Columns 5 and 6 reproduce Columns 3 and 4 (respectively), but use MSA instead of local area. Column 1 includes no controls. To account for differential timing of the treatment letter send dates, Columns 2-6 include controls for the wave of the experiment as well as the number of post-treatment months that each household had to (potentially) respond to treatment. In addition, Columns $2-6$ include fixed effects at the month-year-ZIP5 level using the install date. All standard errors are robust to heteroskedasticity. We exclude households with IHEAs prior to treatment or after the end of the observation period (a total of 1,548 households). Neither above- nor below-median models include households within the median (fifth) decile.

$* * *$ significant at the $1 \%$ level, $* *$ significant at the $5 \%$ level, $*$ significant at the $10 \%$ level. 


\section{Appendix}

\section{Power Tests}

In choosing the size of our treatment and control groups we performed power tests for each variable in order to determine the likelihood of discriminating effect sizes of economic significance. We briefly summarize those power tests here.

The auditor reported that the average monthly rate at which households in our sample sign up for IHEAs was around $0.1 \% \cdot{ }^{28}$ In conversations with the auditing agency in our study region, they said an optimistic expectation would be for treatment to cause IHEA rates to double. As a result, we assume in our IHEA calculations that signup rates will average $.19 \%$ (e.g., a marginal effect of $.09 \%$ ) meaning that IHEA probabilities increase by roughly $90 \%$ with treatment.

Our control group is roughly 50,000 households and the average treatment group is roughly 4600 households (total of 55,200 households). For our power tests, we assign binary IHEA uptake decisions to simulated treatment and control households according to a binomial distribution with the uptake probabilities for treatment and control households as described above. We then estimate the marginal effect of being in any treatment group on IHEA uptake (i.e., pooled treatment versus control). We reject the null hypothesis of zero effect in $98 \%$ of cases. As a result, we will very clearly be able to tell if the field experiment had any effect when we aggregate all treatment cells.

When we perform the same exercise, disaggregating by treatments so that there are only 4600 treated households per treatment, we reject the null hypothesis in only $41 \%$ of cases. The main difference is the precision of the estimates: while the mean coefficient estimate is the same across both power tests, the estimated t-stat of the marginal effect of treatment in the single treatment is roughly one third of the t-stat when all treated groups are aggregated into a single large treated

\footnotetext{
${ }^{28}$ In our data covering the duration of the experiment the rate of audit uptake in the control was in fact around half that rate.
} 
group (e.g., roughly 1.76, sitting just significant at the $10 \%$ level). Aggregating across signal types or subsidy levels, improves the power greatly: the average t-stat is 2.67 and we are able to reject the null hypothesis of zero effect $71.5 \%$ of the time.

In sum, then, we are reasonably confident that we will be able to detect an effect of treatment on IHEAs given the size of our field experiment when treatments are aggregated across signals and less so for individual treatments of each of the twelve treatments. As a result, we are willing to cautiously consider treatment effects that are significant at the $10 \%$ level as significant rather than noise. That said, we take great care in trying to eliminate noise in both the treatment and control group in robustness checks. For example, we remove around 3,000 returned letters by hand and remove all households who had an IHEA within the previous 18 months of the start of the field experiment. Doing this effectively increases the size of each treatment group by $10 \%$ and the size of the control by $5 \%$. The effect of doing so increases the average estimated t-stat to 1.83 (up from 1.76) and the percent of successfully rejected null hypotheses to $43 \%$ (up from $41 \%$ ). There was a similar increase when aggregating across prices for a given comparison so that we reject the null hypothesis of no effect roughly $75 \%$ of the time for each individual comparison.

Given the results of these power tests, distinguishing different treatment effects across individual treatments (e.g., different signal types) requires that treatment vary by at least a factor of two (e.g., the ATE for one of the twelve treatments is twice the ATE for another) to expect that we find any significant effect across individual treatments. These results also motivate our empirical specification to allow the price of the subsidy enter parametrically rather than use indicators for all twelve treatments.

\section{Model of Audits as Search}

To fix ideas, we present a simplified version of the search model in Gilbert et al. (2015). Our aim is not to provide a rigorous theoretical model to derive testable predictions. Rather, we aim to 
motivate how IHEAs are a form of search and develop a framework that links our treatments to search intensity and the subsequent purchase of durable goods.

Assume that conditional on household $i$ 's (observable and unobservable) characteristics $\theta_{i}$, monthly electricity bills are a random draw from the time-invariant distribution: $\forall t, e_{t} \mid \theta_{i} \sim$ $N\left(\mu_{i}\left(\theta_{i}\right), r\right)$ where $r$ is the precision (i.e., the inverse of the variance) of the conditional distribution of electricity bills. ${ }^{29}$ The mean of the distribution $\mu_{i}(\cdot)$ is modelled as a function of $\theta_{i}$, e.g., consumers living in older houses are likely to have higher bills on average, ceteris paribus. While household $i$ knows its own characteristics $\theta_{i}$ with certainty, it has uncertainty over $\mu_{i}(\cdot)$. In particular, household $i$ has priors over $\mu_{i}(\cdot)$ described by $F\left(\mu_{i}(\cdot)\right)$ which the household forms by observing household characteristics (e.g., $\theta_{i}$ ) and updates these beliefs by using monthly electricity bills $e_{t}$ to form posteriors using Bayes' rule. As a result, home owners who have lived in their homes for a longer period of time will have a better idea of their average electricity use than do counterparts who have lived in their home for a shorter period.

Purchasing an energy-efficient durable good serves to reduce mean electricity use by a factor of $\alpha \in(0,1)$ with probability $\rho$. After a purchase, a household with characteristics $\theta_{i}$ will see mean electricity bills drop to $(1-\alpha) \mu_{i}\left(\theta_{i}\right)$ with probability $\rho$ and remain at $\mu_{i}\left(\theta_{i}\right)$ with probability $1-\rho$. Therefore, households are uncertain about the benefits of making an investment in a durable good that is expected to improve energy efficiency. To resolve this uncertainty, a household can conduct an IHEA for a cost $c$ and learn whether or not an energy efficient upgrade lowers their mean electricity use. IHEAs thus serve to eliminate uncertainty about the benefits associated with the purchase of any given durable good. In this regard, IHEAs are akin to expert advice in models such as Pitchik and Schotter (1987) and Edo and Szentes (2007) - the households pays a fixed cost

\footnotetext{
${ }^{29}$ For simplicity, we follow Gilbert et al. (2015) and do not model the choice problem underlying monthly energy use.
} 
to the auditor as a way to resolve uncertainty before making a purchase decision. ${ }^{30}$

Our experimental design, which we discuss in detail in Section IV, provides exogenous variation over key parameters of this model. Our subsidy treatments provide exogenous variation in the cost of an audit, $c$. In doing so, we generate exogenous variation in the expected net benefits of getting an audit. Hence, we would expect to see increased participation in the IHEA for households in our Subsidy treatments. Our Social Comparison treatments introduce random variation in what households know about their consumption relative to the average consumption of their neighbors. In our framework, this information could impact the household's expected gains from an audit in two ways. First, households may use information on relative usage to update their beliefs about the probability that an install would result in savings $(\rho)$ and/or the expected reductions in energy use from a successful install $(\alpha)$. We are agnostic about the precise channel since our data do not allow us to observe and model belief updating. Yet it is important to note that if a household were to observe they are below mean local area use, it is plausible that the household would update their beliefs such that it reduces the expected benefits of an audit. Second, it is possible that Social Comparisons introduce a form of moral suasion that is akin to the social pressure term in DellaVigna et al. (2012). If so, households may schedule an audit as a way to alleviate feelings of guilt that are triggered upon learning that their consumption exceeds that of similar neighbors. However, as the underlying decision to search is driven by the expected costs of not searching as opposed to the expected benefits of search, such motives may lead to lower rates of purchase as such individuals are searching for the "wrong" reasons.

\footnotetext{
${ }^{30}$ This simple model has two notable shortcomings. First, there are well-known discounting issues in durable good purchases known as the energy paradox. In the context of our field experiment, though, this is second order since any discounting issues are shared by both the treatment and control groups. Second, the binomial distribution of $\alpha$ is very much a simplifying abstraction. A richer model would offer a continuous distribution which is itself a function of $\theta_{i}$. However, the important characteristic of the model- uncertainty over benefits of an audit- is verified in data we show below, e.g., incomplete install rates.
} 
Month Day, Year

Dear Valued Customer,

There's no place like home, and there's no time like now to make your home more energy efficient. You can conserve energy, save on utility bills, and get cash rebates by participating in

. If you qualify, you can also use on-bill financing to pay for

improvements.

If you sign up for an

convenient for you. The advisor will recommend cost-effective ways to increase your home's energy efficiency and will install free CFLs and low-flow water saving measures if you choose.

The evaluation fee is $\$ 150$ (currently with an instant rebate of $\$ 100$ ). And you will receive the remaining $\$ 50$ fee back if you spend $\$ 150$ or more on qualifying improvements. You will also receive matching rebates of up to $\$ 500$ for installing eligible improvements. As an additional thank you for participating, if you have an In-Home Energy Evaluation within 30 days from the date of this letter you will receive a $\$ 50$ gift card.

We thought that you might be interested in the following information about your energy usage last year:

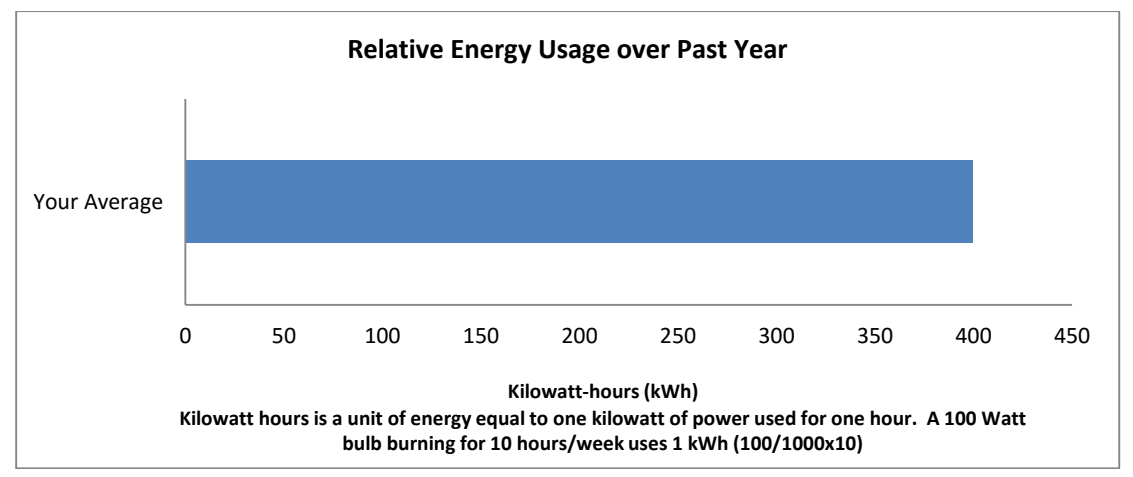

Your average energy consumption over the past year: $400 \mathrm{kWh}$

For more information about the program, including on-bill financing, call information about the program and details about qualifying improvements by following the link on the home page.

Sincerely,

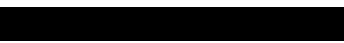

NC123

Figure A1: No Comparison Letter Example with $\$ 50$ Subsidy Offer 
Month Day, Year

Dear Valued Customer,

There's no place like home, and there's no time like now to make your home more energy efficient. You can conserve energy, save on utility bills, and get cash rebates by participating in

program. If you qualify, you can also use on-bill financing to pay for

improvements.

If you sign up for

$$
\text { a } \square \text { Certified Energy Advisor will visit your home at a time }
$$

convenient for you. The advisor will recommend cost-effective ways to increase your home's energy efficiency and will install free CFLs and low-flow water saving measures if you choose.

The evaluation fee is $\$ 150$ (currently with an instant rebate of $\$ 100$ ). And you will receive the remaining $\$ 50$ fee back if you spend $\$ 150$ or more on qualifying improvements. You will also receive matching rebates of up to $\$ 500$ for installing eligible improvements. As an additional thank you for participating, if you have an In-Home Energy Evaluation within 30 days from the date of this letter you will receive a $\$ 50$ Visa gift card.

We thought that you might be interested in the following information about your energy usage last year:

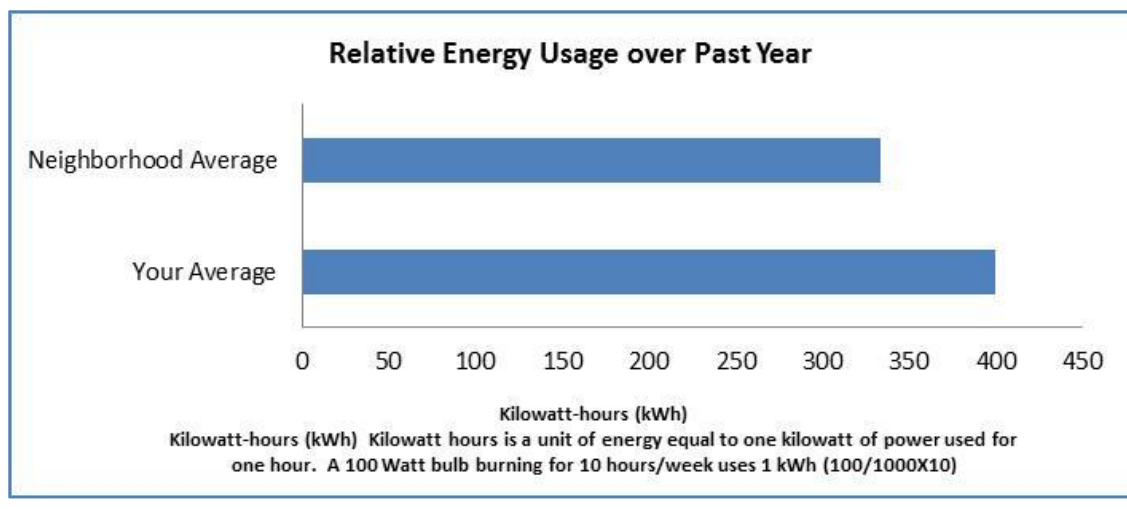

Your Average Energy Usage

$400 \mathrm{kWh}$

Local Area Homes' Average Energy Usage

$333 \mathrm{kWh}$

You consumed $20 \%$ more energy than other area homes.

For more information about the

program, including on-bill financing, call

You can also find more information about the program and details about qualifying improvements by following the link on the home page.

Sincerely,

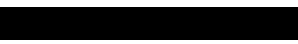

kWh123

Figure A2: kWh Comparison Letter Example with $\$ 50$ Subsidy Offer 
Month Day, Year

Dear Valued Customer,

There's no place like home, and there's no time like now to make your home more energy efficient. You can

conserve energy, save on utility bills, and get cash rebates by participating in
program. If you qualify, you can also use on-bill financing to pay for $\quad$ improvements.

If you sign up for an $\quad$ a a Certified Energy Advisor will visit your home at a time

convenient for you. The advisor will recommend cost-effective ways to increase your home's energy efficiency and will install free CFLs and low-flow water saving measures if you choose.

The evaluation fee is $\$ 150$ (currently with an instant rebate of $\$ 100$ ). And you will receive the remaining $\$ 50$ fee back if you spend $\$ 150$ or more on qualifying improvements. You will also receive matching rebates of up to $\$ 500$ for installing eligible improvements. As an additional thank you for participating, if you have an In-Home Energy Evaluation within 30 days from the date of this letter you will receive a \$20 gift card.

We thought that you might be interested in the following information about your energy bills last year:



*Dollars per month calculated at \$.XX per kWh

Your Average Energy Bill

Local Area Homes' Average Energy Bill
$\$ 42.50$

$\$ 33.28$

You spent $28 \%$ more dollars than other area homes.

For more information about the $\square$ program, including on-bill financing, call $\ldots$. You can also find more information about the program and details about qualifying improvements by following the link on the home page.

Sincerely,

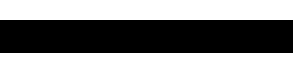

Ex2123

Figure A3: $\$$ Comparison Letter Example with $\$ 20$ Subsidy Offer 
Month Day, Year

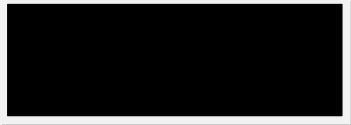

Dear Valued Customer,

There's no place like home, and there's no time like now to make your home more energy efficient. You can conserve energy, save on utility bills, and get cash rebates by participating in

program. If you qualify, you can also use on-bill financing to pay for $\quad$ improvements.

If you sign up for an $\quad$ a $\square$ Certified Energy Advisor will visit your home at a time

convenient for you. The advisor will recommend cost-effective ways to increase your home's energy efficiency and will install free CFLs and low-flow water saving measures if you choose.

The evaluation fee is $\$ 150$ (currently with an instant rebate of $\$ 100$ ). And you will receive the remaining $\$ 50$ fee back if you spend $\$ 150$ or more on qualifying improvements. You will also receive matching rebates of up to $\$ 500$ for installing eligible improvements. [NO GIFT CARD REBATE]

We thought that you might be interested in the following information about the $\mathrm{CO} 2$ created through your energy consumption last year. Carbon emissions can best be defined as carbon substances which end up in the atmosphere. Such gases are produced by many things including cars, industrial plants and electricity production.



Your Energy Use

Local Area Homes' Energy Use
$500 \mathrm{kWh}$ created $1,085 \mathrm{lbs}$ of $\mathrm{CO} 2$ emissions

$600 \mathrm{kWh}$ created $1,302 \mathrm{lbs}$ of $\mathrm{CO} 2$ emissions

You produced $20 \%$ more $\mathrm{CO}$ emissions than other area homes.

For more information about the

program, including on-bill financing, call

You can also find more

information about the program and details about qualifying improvements by following the link on the home page.

Sincerely,

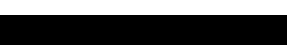

$\mathrm{CO} 2123$

Figure A4: $\mathrm{CO}_{2}$ Comparison Letter Example with No Subsidy Offer 
Figure A5: Treatment Assignment (Proportion) by Local Decile of Pre-Treatment Use

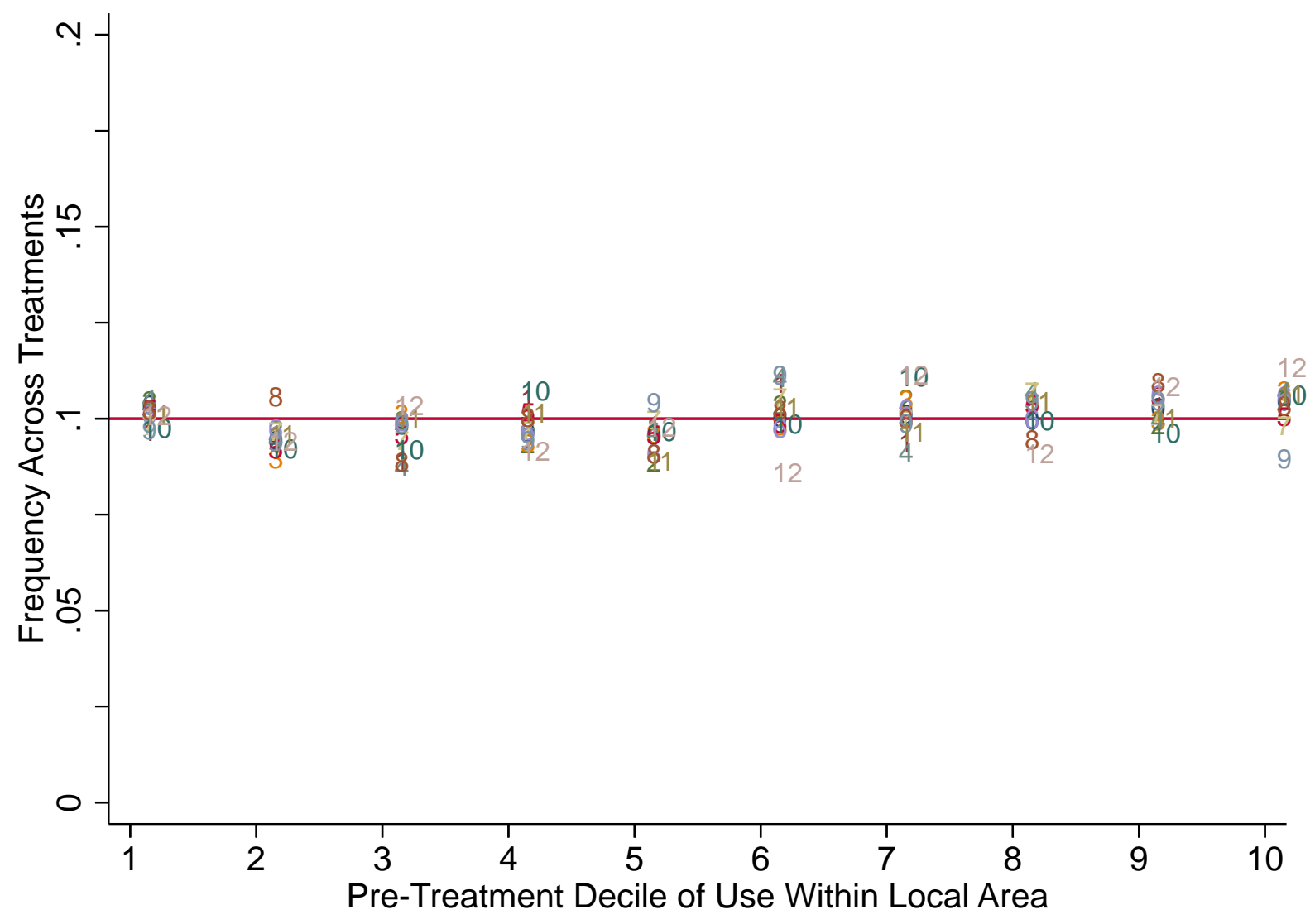

Note: The figure summarizes one measure of balance of treatment assignment along the decile of pre-treatment use within a local area (either nine or five digit ZIP). Exact balance across all 13 treatments cells (control and 12 treatment letters) would require each decile represent 1/10 (the solid red line) of the assigned households for each treatment. Actual treatment assignment proportions can be identified by the treatment number. The control group is denoted as 0 . Along the subsidy dimension: a) households receiving no subsidy are in treatments 1 through 4 , b) households receiving a $\$ 20$ subsidy are in treatments 5 through 8 , and c) households receiving a $\$ 50$ subsidy are in treatments 9 through 12. Along the content dimension: a) households receiving a "No Comparison" letter are in treatments 1,5, and 9, b) households receiving a kWh Comparison letter are in treatments 2, 6, and 10, c) households a receiving $\$$ Comparison letter are in treatments 3,7 , and 11 , and d) households receiving a $\mathrm{CO}_{2}$ Comparison letter are in treatments 4, 8, and 12 . 
Table A1: Impact of Treatment Letter and Subsidy on IHEA Uptake Rates (Saturated Model)

\begin{tabular}{|c|c|c|c|c|c|c|}
\hline & 1 & 2 & 3 & 4 & 5 & 6 \\
\hline No Comparison - No Subsidy & $\begin{array}{l}-0.0003 \\
(0.0005)\end{array}$ & $\begin{array}{l}-0.0004^{*} \\
(0.0002)\end{array}$ & $\begin{array}{l}-0.0004 \\
(0.0004)\end{array}$ & $\begin{array}{l}-0.0001 \\
(0.0001)\end{array}$ & $\begin{array}{l}-0.0004 \\
(0.0004)\end{array}$ & $\begin{array}{l}-0.0002 \\
(0.0001)\end{array}$ \\
\hline kWh Comparison - No Subsidy & $\begin{array}{c}0.0010 \\
(0.0008)\end{array}$ & $\begin{array}{c}0.0002 \\
(0.0003)\end{array}$ & $\begin{array}{l}-0.0002 \\
(0.0003)\end{array}$ & $\begin{array}{c}0.0003 \\
(0.0003)\end{array}$ & $\begin{array}{l}-0.0001 \\
(0.0003)\end{array}$ & $\begin{array}{c}0.0003 \\
(0.0003)\end{array}$ \\
\hline \$ Comparison - No Subsidy & $\begin{array}{c}0.0005 \\
(0.0007)\end{array}$ & $\begin{array}{c}0.0002 \\
(0.0003)\end{array}$ & $\begin{array}{c}0.0003 \\
(0.0005)\end{array}$ & $\begin{array}{c}0.0001 \\
(0.0002)\end{array}$ & $\begin{array}{c}0.0001 \\
(0.0005)\end{array}$ & $\begin{array}{c}0.0005 \\
(0.0004)\end{array}$ \\
\hline $\mathrm{CO}_{2}$ Comparison - No Subsidy & $\begin{array}{l}-0.0005 \\
(0.0006)\end{array}$ & $\begin{array}{l}-0.0000 \\
(0.0002)\end{array}$ & $\begin{array}{l}-0.0003 \\
(0.0002)\end{array}$ & $\begin{array}{c}0.0001 \\
(0.0001)\end{array}$ & $\begin{array}{l}-0.0002 \\
(0.0002)\end{array}$ & $\begin{array}{c}0.0001 \\
(0.0002)\end{array}$ \\
\hline No Comparison - $\$ 20$ Subsidy & $\begin{array}{c}0.0001 \\
(0.0004)\end{array}$ & $\begin{array}{l}-0.0001 \\
(0.0003)\end{array}$ & $\begin{array}{c}0.0001 \\
(0.0004)\end{array}$ & $\begin{array}{l}-0.0000 \\
(0.0003)\end{array}$ & $\begin{array}{c}0.0002 \\
(0.0003)\end{array}$ & $\begin{array}{l}-0.0001 \\
(0.0003)\end{array}$ \\
\hline kWh Comparison - $\$ 20$ Subsidy & $\begin{array}{l}0.0011^{*} \\
(0.0006)\end{array}$ & $\begin{array}{c}0.0000 \\
(0.0002)\end{array}$ & $\begin{array}{l}-0.0003 \\
(0.0003)\end{array}$ & $\begin{array}{r}-0.0003^{*} \\
(0.0002)\end{array}$ & $\begin{array}{l}-0.0001 \\
(0.0003)\end{array}$ & $\begin{array}{r}-0.0003^{*} \\
(0.0002)\end{array}$ \\
\hline$\$$ Comparison - $\$ 20$ Subsidy & $\begin{array}{c}0.0021^{* * *} \\
(0.0007)\end{array}$ & $\begin{array}{l}0.0006^{*} \\
(0.0003)\end{array}$ & $\begin{array}{c}0.0003 \\
(0.0004)\end{array}$ & $\begin{array}{c}0.0002 \\
(0.0002)\end{array}$ & $\begin{array}{c}0.0005 \\
(0.0004)\end{array}$ & $\begin{array}{c}0.0004 \\
(0.0003)\end{array}$ \\
\hline $\mathrm{CO}_{2}$ Comparison - $\$ 20$ Subsidy & $\begin{array}{c}0.0007 \\
(0.0008)\end{array}$ & $\begin{array}{c}0.0004 \\
(0.0003)\end{array}$ & $\begin{array}{c}0.0005 \\
(0.0004)\end{array}$ & $\begin{array}{l}-0.0001 \\
(0.0003)\end{array}$ & $\begin{array}{c}0.0005 \\
(0.0004)\end{array}$ & $\begin{array}{l}-0.0001 \\
(0.0003)\end{array}$ \\
\hline No Comparison - $\$ 50$ Subsidy & $\begin{array}{c}0.0003 \\
(0.0006)\end{array}$ & $\begin{array}{c}0.0002 \\
(0.0003)\end{array}$ & $\begin{array}{c}0.0002 \\
(0.0005)\end{array}$ & $\begin{array}{l}-0.0001 \\
(0.0001)\end{array}$ & $\begin{array}{c}0.0002 \\
(0.0005)\end{array}$ & $\begin{array}{l}-0.0001 \\
(0.0001)\end{array}$ \\
\hline kWh Comparison - $\$ 50$ Subsidy & $\begin{array}{c}0.0025^{* *} \\
(0.0011)\end{array}$ & $\begin{array}{l}0.0012^{* *} \\
(0.0005)\end{array}$ & $\begin{array}{c}0.0005 \\
(0.0005)\end{array}$ & $\begin{array}{l}-0.0001 \\
(0.0001)\end{array}$ & $\begin{array}{c}0.0005 \\
(0.0005)\end{array}$ & $\begin{array}{l}-0.0001 \\
(0.0001)\end{array}$ \\
\hline$\$$ Comparison - $\$ 50$ Subsidy & $\begin{array}{c}0.0011 \\
(0.0008)\end{array}$ & $\begin{array}{c}0.0003 \\
(0.0003)\end{array}$ & $\begin{array}{l}-0.0005 \\
(0.0003)\end{array}$ & $\begin{array}{c}0.0013^{* *} \\
(0.0006)\end{array}$ & $\begin{array}{l}-0.0004 \\
(0.0003)\end{array}$ & $\begin{array}{l}0.0013^{* *} \\
(0.0006)\end{array}$ \\
\hline $\mathrm{CO}_{2}$ Comparison - $\$ 50$ Subsidy & $\begin{array}{l}-0.0005 \\
(0.0006)\end{array}$ & $\begin{array}{l}-0.0000 \\
(0.0002)\end{array}$ & $\begin{array}{l}-0.0003 \\
(0.0002)\end{array}$ & $\begin{array}{c}0.0001 \\
(0.0001)\end{array}$ & $\begin{array}{l}-0.0002 \\
(0.0002)\end{array}$ & $\begin{array}{c}0.0001 \\
(0.0002)\end{array}$ \\
\hline Constant & $\begin{array}{c}0.0011^{* * *} \\
(0.0001)\end{array}$ & & & & & \\
\hline Audit Month-Year by ZIP5 & No & Yes & Yes & Yes & Yes & Yes \\
\hline Wave & No & Yes & Yes & Yes & Yes & Yes \\
\hline Sample & $\begin{array}{c}\text { Full } \\
\text { Sample }\end{array}$ & $\begin{array}{c}\text { Full } \\
\text { Sample }\end{array}$ & $\begin{array}{c}\text { Above } \\
\text { Local Median }\end{array}$ & $\begin{array}{c}\text { Below } \\
\text { Local Median }\end{array}$ & $\begin{array}{c}\text { Above } \\
\text { MSA Median }\end{array}$ & $\begin{array}{c}\text { Below } \\
\text { MSA Median }\end{array}$ \\
\hline $\begin{array}{l}R^{2} \\
\mathrm{~N}\end{array}$ & $\begin{array}{l}0.0004 \\
99,000\end{array}$ & $\begin{array}{l}0.6950 \\
98,952\end{array}$ & $\begin{array}{l}0.7559 \\
50,426\end{array}$ & $\begin{array}{l}0.7284 \\
38,978\end{array}$ & $\begin{array}{l}0.7478 \\
50,859\end{array}$ & $\begin{array}{l}0.7251 \\
38,253\end{array}$ \\
\hline
\end{tabular}

Note: Dependent variable is an indicator for households that completed an IHEA within 60 days of being randomized to receive a treatment letter (or be part of the control group). Rows are indicator variables on each of the 12 unique treatments. Columns 1 and 2 are estimated on the full sample of households. Column 3 is estimated on the restricted sample of households with average pre-experiment use above the median in their local area. Column 4 is estimated on the restricted sample of households with average pre-experiment use below the median in their local area. Columns 5 and 6 reproduce Columns 3 and 4 (respectively), but use MSA instead of local area. Column 1 includes no controls. Columns 2-6 include controls for the wave of the experiment as well as month-year-ZIP5 level using the IHEA date. All standard errors are robust to heteroskedasticity. We exclude households with IHEAs prior to treatment or after the end of the observation period (a total of 1,548 households). Neither above- nor below-median models include households within the median (fifth) decile.

$* * *$ significant at the $1 \%$ level, $* *$ significant at the $5 \%$ level, $*$ significant at the $10 \%$ level. $* * *$ significant at the $1 \%$ level, $* *$ significant at the $5 \%$ level, $*$ significant at the $10 \%$ level. 